Department of Energy

Office of Environmental Management (DOE-EM)

\title{
2009 DOE-EM
}

\section{Long-Term Monitoring} Technical Forum

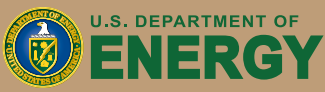

Office of

Summary Report

Paper and electronic copies of

September 2009

Savannah River National Laboratory

Savannah River Nuclear Solutions, LLC

Savannah River Site

Aiken, South Carolina 29808

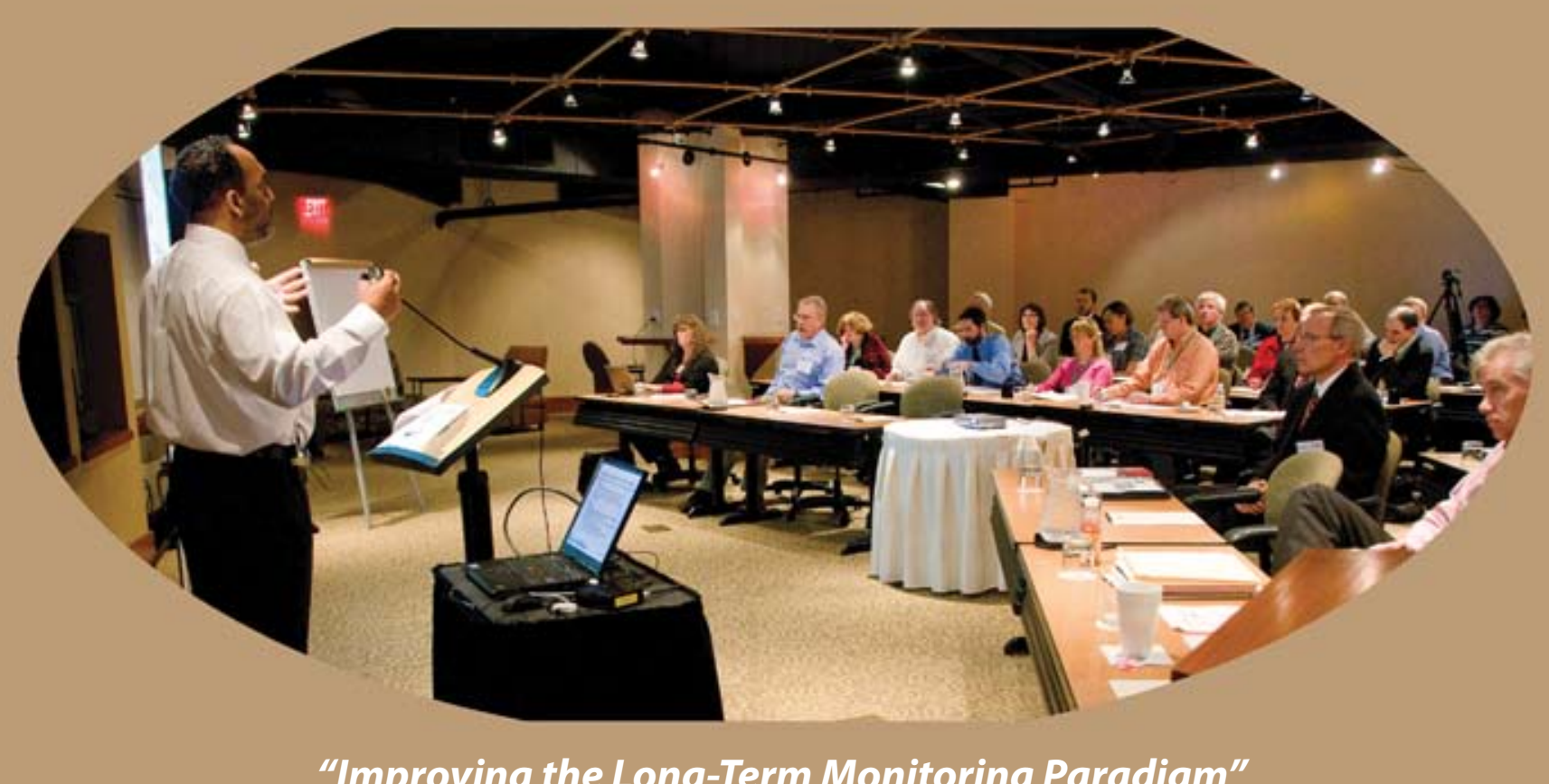

"Improving the Long-Term Monitoring Paradigm" 


\section{DOE-EM}

Long-Term Monitoring

Technical Forum

February 11-12, 2009

Sponsored by

Savannah River National Laboratory and

DOE Office of Environmental Management

Engineering and Technology Program

Summary Report

September 2009 


\section{TABLE OF CONTENTS}

\section{Contract Number}

This document was prepared in conjunction with work accomplished under Contract No. DE-AC09-08SR22470 with the U.S. Department of Energy.

\section{DISCLAIMER}

This work was prepared under an agreement with and funded by the U.S. Government. Neither the U. S. Government or its employees, nor any of its contractors, subcontractors or their employees, makes any express or implied: 1. warranty or assumes any legal liability for the accuracy, completeness, or for the use or results of such use of any information, product, or process disclosed; or 2. representation that such use or results of such use would not infringe privately owned rights; or 3. endorsement or recommendation of any specifically identified commercial product, process, or service. Any views and opinions of authors expressed in this work do

not necessarily state or reflect those of the United States Government, or its contractors, or subcontractors.

EXECUTIVE SUMMARY

INTRODUCTION

BACKGROUND

BREAKOUT SESSION SUMMARIES

LTM Performance Measurement Tools ................................................................................ 9

LTM Systems .

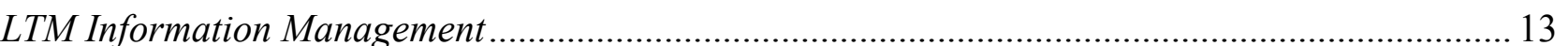

LTM INVESTMENT SECTOR ALLOCATION EXERCISE ................................................................. 19

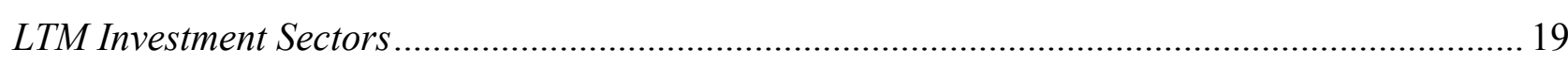

Results

CONCLUSIONS AND SUMMARY OF RECOMMENDED INITIATIVES .......................................... 23

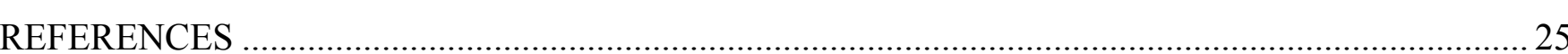

APPENDIX A - List of Participants/Contact Information

APPENDIX B - Summary of Participant Evaluation Forms

APPENDIX C - List of Ideal LTMS Attributes

APPENDIX D - LTM “Bucks” Investment Exercise Demographic Data Sheet

LIST OF FIGURES

Figure 1. Attendee affiliations at the 2009 DOE-EM LTM Technical Forum 5

Figure 2. Illustration of the DOEgle system

Figure 3. Demographic profile of the participants from the LTM Investment Sector Allocation

$$
\text { Exercise.. }
$$

Figure 4. Overall allocation totals for the six investment sectors 


\section{TABLE OF CONTENTS (Continued)}

Figure 5. Investment allocation into top four sectors by affiliation.

Figure 6. Investment allocation into top four sectors by work focus .22

Figure 7. Investment allocation into top four sectors by discipline.

LIST OF TABLES

Table 1. Listing of the LTM Paradigm Improvement Background Description, Initiative Details, and Outcome and Benefits

\section{EXECUTIVE SUMMARY}

The U. S. Department of Energy's (DOE) Office of Environmental Management (EM) has the responsibility for cleaning up 60 sites in 22 states that were associated with the legacy of the nation's nuclear weapons program and other research and development activities. These sites are unique and many of the technologies needed to succes fully disposition the associated wastes have yet to be developed or would require significant re-engineering to be adapted for future EM cleanup efforts.

In 2008, the DOE-EM Engineering and Technology Program (EM-22) released the Engineering and Technology Roadmap in response to Congressional direction and the need to focus on longer term activities required for the completion of the aforementioned cleanup program. One of the strategic initiatives included in the Roadmap was to enance long term performance monitoring as defined by "Develop and deploy cost effective long-term strategies and technologies to monitor closure sites (including soil, groundwater, and surface water) with multiple contaminants (organics, metals and radionuclides) to verify integrated long-term cleanup performance." To support this long-term monitoring (LTM) strategic initiative, EM 22 and the Savannah River National Laboratory (SRNL) organized and held an interactive symposia, known as the 2009 DOE-EM Long-Term Monitoring Technical Forum, to define and prioritize LTM improvement strategies and products that could be realized within a 3 to 5 year investment time frame. This near-term focus on fundamental research would then be used as a foundation for development of applied programs to improve the closure and long-term performance of EM's legacy waste sites.

The Technical Forum was held in Atlanta, GA on February 11-12, 2009, and attended by 57 professionals with a focus on identifying those areas of opportunity that would most effectively advance the transition of the current practices to a more effective strategy for the LTM paradigm. The meeting format encompassed three break-out sessions, which focused on needs and opportunities associated with the following LTM technical areas: (1) Performance Monitoring Tools, (2) Systems, and (3) Information Management.

The specific objectives of the Technical Forum were to identify: (1) technical targets for reducing EM costs for lifecycle monitoring; (2) cost-effective approaches and tools to support the transition from active to passive remedies at EM waste sites; and (3) specific goals and objectives associated with the lifecycle monitoring initiatives outlined within the Roadmap.

The first Breakout Session on LTM performance measurement tools focused on the integration and improvement of LTM performance measurement and monitoring tools that deal with parameters such as ecosystems, boundary conditions, geophysics, remote sensing, biomarkers, ecological indicators and oher types of data used in LTM conhensively dicull A

The second Breakout Session was on LTM systems. The focus of this session was to identify new and inventive LTM systems addressing the framework for interactive parameters such as infrastructure, sensors, diagnostic features, field screening tools, state of the art characterization monitoring systems/concepts, and ecosystem approaches to site conditions and evolution. LTM systems consist of the combination of data acquisition and management efforts, data processing and analysis efforts and reporting tools. The objective of the LTM systems workgroup was to provide a vision and path towards novel and innovative LTM systems, which should be able to provide relevant, actionable information on system performance in a cost-effective manner. Two investment sectors were developed in this Breakout Session.

The last Breakout Session of the Technical Forum was on LTM information management. The session focus was to address data issues such as. efficient management of large and diverse datasets; consistency and comparability in data management and incorporation of accurate historical information; data interpretation and information synthesis including statistical methods, modeling, and visualization; and linage of data to site management objectives and leveraging information to forge consensus among stakeholders. One investment sector was developed in this Breakout Session. 


\section{INTRODUCTION}

Based on the investment sectors identified by the Breakout Sessions, the Technical Forum participants were asked to identify and prioritize those near-term areas to improve the current LTM paradigm. A total of six LTM investment sectors were identified by the three Breakout Sessions. The top four investment sectors chosen by the investment totals allocated by the exercise's participants included, in order of most to least, (1) "DOEgle Environment," (2) Subsurface Remote Sensing and Non-Invasive Techniques, (3) Compliance to Performance Monitoring, and (4)

The fundamental objective in cleaning up and closing a legacy waste site is to achieve performance that will protect the surrounding environment with a long-term focus on health and human safety. LTM is key to verifying the long-

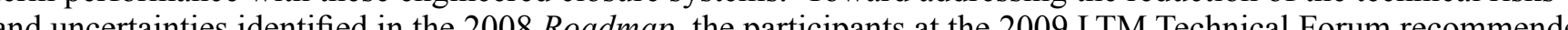
(a) recommended five initiatives. For five Manage will be nitiatives are ine to contribute to the ner-tern DOE's success in cleaning up the legacy waste sites.

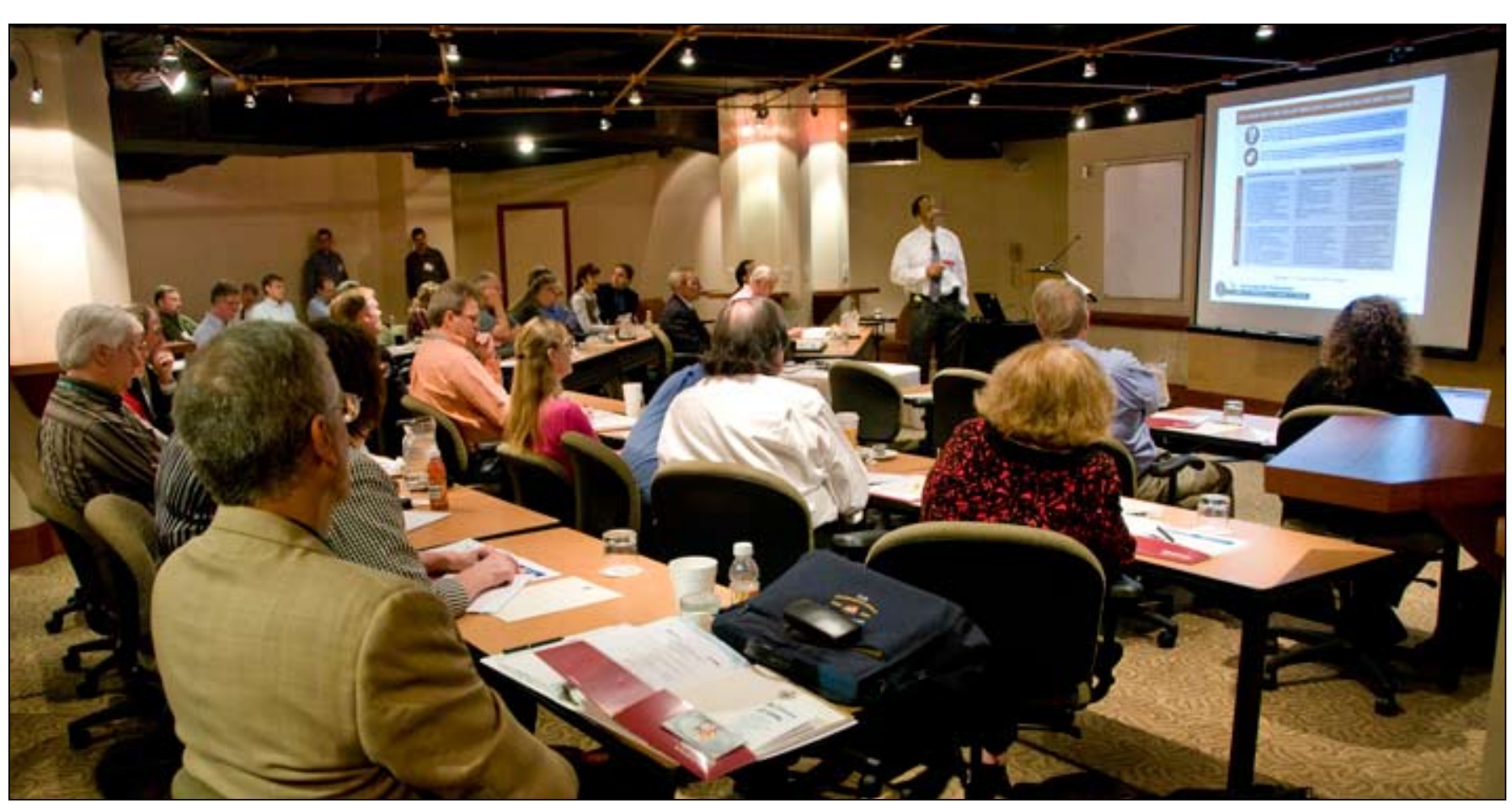

The U. S. Department of Energy's (DOE) Office of Environmental Management (EM) has the responsibility for cleaning up 60 sites located in 22 states, which collectively encompass over 200 subsurface contaminated plumes. These sites were variously associated with the legacy of the nation's nuclear weapons program as well as other DOE research and development activities. "Protecting the environment by providing a responsible resolution to the environmental legacy of nuclea weapons production "is one of DOE's five strategic themes (DOE 2006). The primary challenge related to the cleanup of these sites and achieving the resolution of that associated strategic theme is driven by important fundamental questions that remain largely unanswered. These would include questions such as:

- What and how does one monitor to ensure that a closure system is performing correctly?

- What are the risks to the human and natural environments if that system fails?

- Can one realistically expect these systems to continue working and be sustainable for possibly up to tens of thousands of years?

Within DOE the terms "environmental stewardship" and "long-term stewardship" refer to the mechanisms necessary to ensure both short- and long-term protection of the public and the environment after initial cleanups at facilities in the DOE Complex have reached closure.
These mechanisms include physical and institutional controls, information management, environmental monioring, and risk assessment. The U. S. Department of Defense (DoD) faces similar issues in the post-closure, period of its cleanups. The emergence of "stewardship" long-term performance of remedies and the effects of now. Stewardship encompasses many daunting technical issues, including:

- Understanding and monitoring material deterioration in barriers and closure system

Managing and maintaining critical information systems with access for future generations, and decades.

The need to reduce the costs of stewardship, while providing acceptable risks to the public, drives DOE to create new approaches.

The DOE's contaminated sites are unique in three ways as follows: (1 waste (mixed radiation/chemical), and (3) quantities of waste (Gochfeld et al. 2007). Many of the programs to treat, dispose and monitor these waste types and volumes unique to DOE have been "first-of-a-kind" and, pects a shift in the federal view from the short-term cleanup perspective of the past decade to a focus on the 
as such, are unprecedented in their scope and complexity. The successful closure of these waste sites so that
human and ecological exposure is limited for extremely long periods of time represents an unprecedented engineering challenge. This has meant that many of the technologies needed to successfully disposition these wastes have yet to be developed or require significan re-engineering to be adapted for EM's cleanup efforts. As such, DOE faces a long-term and costly challenge to assure sustainable protectiveness at these sites. Th will include not only traditional risk methodologies, but also the assessment and surveillance necessary for
stewards for long-term monitoring (LTM) of risk from stewards for long-term monitoring (LTM) of risk from protectiveness (Gochfeld et al. 2007).

Although great steps forward has been made toward safely disposing of this legacy waste, much remains to challenges will require a strong and responsive applied research and engineering program. To address these needs, DOE-EM has placed this responsibility within the Engineering and Technology Program (EM-22). Part of EM 22's mission is to provide DOE with the best-in-class engineering foundation, technical assistance, and new technologies to reduce costs and schedules for completion of the DOE mission to successfully disposition legacy waste and close the associated sites.

In a recent report (NRC 2005), the National Research Council recommended that "an improved capability for environmental monitoring would strengthen EM"s plans to leave waste and contaminated media at DOE sites." In addition, the report stated that "Monitoring system at EM closure sites have been estimated to be some 25 years behind the state-of-art." Reliable and scientifically-sound LTM of these closure sites is necessary to verify the successful performance of the implemented cleanup. LTM activities consist primarily of ensuring hat use restrictions remain in force and maintaining Environ to prot pu is a citic and the environent. waste site cleanup/closure for three reasons: (1) data provide ongoing evidence of environmest (1) pind protection of the public and the environ conplanoe monitoring program, in part, determines the life cycle cost and extent of stewardship; and (3) the monitoring program provides a framework to develop trust and agreement between the site steward, stakeholders, an public (Moore et al. 2001). Many of these cleanup efforts will require the need for extensive monitoring an long-term stewardship actions, including surveillance and maintenance of installed structures and systems. In most cases, these sites will have to continue to maintain surveillance/maintenance and environmental monitoring activities to ensure regulatory compliance for an unspecified number of years in the future. Such efforts are not insignificant, with typical LTM costs estimated to be over one-third of the total hife-cycle cost of cleanup at most DOE sites. To be successful in these cleanup LTM paradigm to be used by EM must be improved.

In 2008, prepared in response to Congressional direction and the need to focus on longer term activities require for the completion of the cleanup program, EM-22 released the Engineering and Technology Roadmap inititives aimed at reducing the technical trate uncertainties associated with cleaning up legacy waste over the next ten years. The Roadmap also proposes how these strategies would be implemented. Within the Integration and Cross Cutting Initiatives Program Area, one of the Technical Risk and Uncertainties in Assessing Long-Term Performance was that "Inadequate long-term monitoring and maintenance strategies and technologies to verify cleanup performance could potentially invalidate the selected remedy and escalate cleanup costs." The associated strategic initiative to enhance long term performance monitoring was to "Develop and deploy cost-effective long-term strategies and technologies to monitor closure sites (including soil, groundwater, an surface water) with multiple contaminants (organics, metals and radionuclides) to verify integrated long-term cleanup performance." To support this cross-cutting initiative from the Roadmap, EM-22, in collaboration with the DOE Offices of Science and Legacy Management (LM), decided to host an interactive forum to identify technical solutions that would advance the LTM paradigm for EM waste sites. The overarching goal of this technical forum was to define and prioritize EM to 5 yes and products that conld be realized within a 3

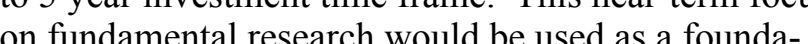
tion for directed research and development efforts in longerterm, which would be directly and ingedinely transferred to the applied programs.

The "2009 DOE-EM Long-Term Monitoring Technical Forum" sponsored by DOE-EM and the Savann River National Laboratory (SRNL), was held in Atlanta, GA on February 11-12, 2009. The meeting was attended by 57 professionals (see Fig. 1; Appendix A) with a focus on identifying those areas of opportunity

\section{Academic Institutions}

$16 \%$

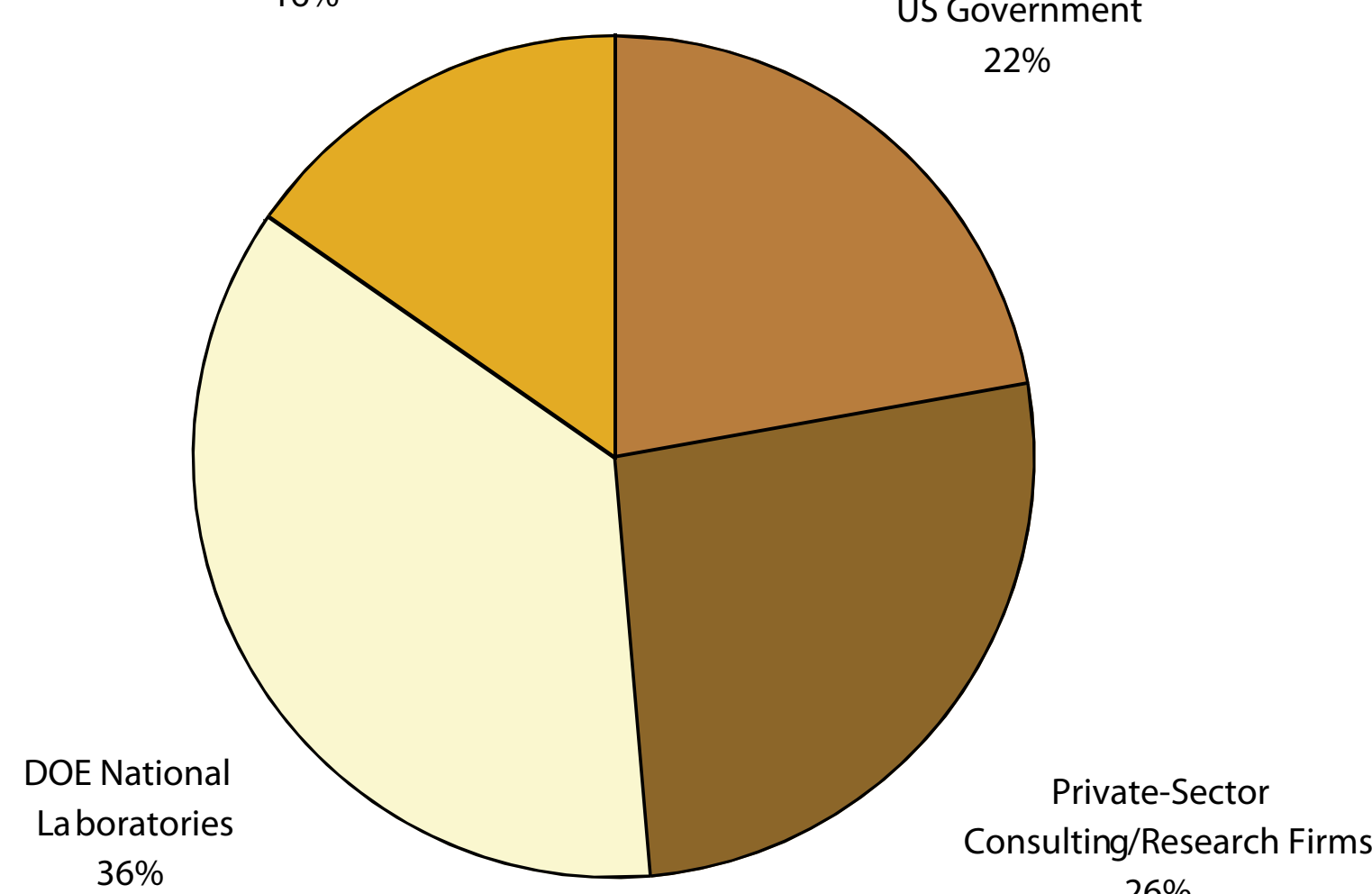

Figure 1. Attendee affiliations at the 2009

DOE-EM LTM Technical Forum.

that would most effectively advance the transition from current practices to a more effective LTM strategy. The meeting was accomplished through three break-out sessions, which focused on needs and opportunities associated with the following LTM technical areas: (1) Performance Monitoring Tools, (2) Systems, and (3) Information Management. The results of the Breakout ed to the were consolidated into iniliatives and presentThe specifc objectives of the Techncal Forn were

The specific objectives of the Technical Forum were to identify:

- Technical targets for reducing EM costs for life-cycle monitoring, which typically represent as much as one-third of the overall life-cycle estimate for

EM waste sites;
- Cost-effective approaches and tools to support the transition from active to passive remedies, such as monitored natural attenuation (MNA), at EM wast sites; and

- Specific goals and objectives associated with the lifecycle monitoring initiatives outlined within the Roadmap

This report represents the summary document of the re. Sessions. The Technical Forum was also evaluated by the participants as to the structure, scope and success. The results of that evaluation are provided in Appendix B. 


\section{BACKGROUND}

This page intentionally left blank

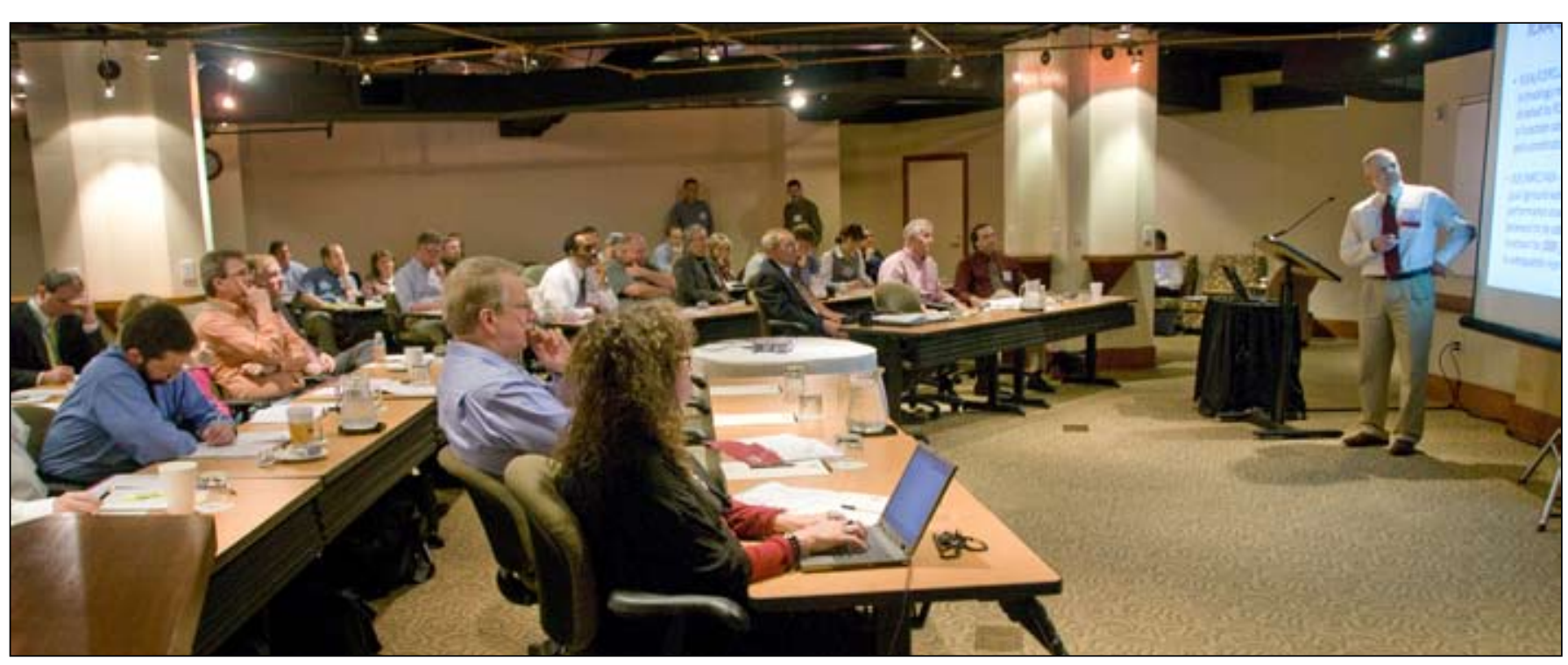

Throughout EM's history, over one-third of the "needs statements" collected from the EM operating divisions have been related to tron the EM to suppong vivisions and validation of remedial performance (Looney 2002). About half of those needs were for improvements of sensor and detection methods for specific contaminants. The remainder of the needs were for general detection capabilities, system infrastructure, and sensors/systems for hydrogeologic parameters, microbiology/geochemistry processes, fluxes, and surrogate parameters. This latter grouping may be of particular interest for LTM applications. All of the contaminated ground water plumes identified in the DOE complex will require verification of cleanup and acceptable risk performance over tens of years beyond final cleanup at a total projected cost in excess of $\$ 2$ billion. Much of this cost is associated with frequent analyses of contamination in a large number of monitoring wells. Such measurements are expensive and the resulting datasets have been determined to be inefficient and often inadequate for meeting LTM objectives. The tabulated cost above do not include closure monitoring of Uranim Mill Tail-

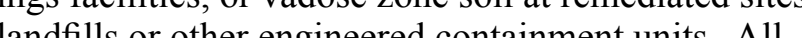
land cost effective, LTM activities. Additionlly, stakeholdAdvis status and that they are "safe."

In response to these challenges, EM operating contractors have worked with regulators to implement several types of improvements in LTM systems. These improvements include: (1) developing and negotiating

cal and scientific tools to optimize monitoring networks, sampling frequency, and data interpretation. Area Closure strategies support improving future efficiency monitoring by combining efforts for co-located and closely spaced facilities. System optimization methods have yielded significant benefit by reducing sampling and analytical costs. Importantly, the potential for continued improvement using these two strategies is constrained by their tight linkage to traditional monitoring well based systems. Thus, technical challenges and opportunities remain in EM LTM activities, primarily in expanding monitoring approaches to allow altenative but improved paradigms. The need for such devel-

opment is highlighted in several recent independent reviews of DOE-EM programs by the National Research Council of the National Academies (e.g., NRC 2000, 2005a, 2005b)

A central tenant of the EM applied science program related to LTM is developing systems to provide straightforward and compelling information at a reasonable cost. An expanded set of technologies that go beyond visioned as described below. The primary consideration in selecting and assembling tochnologies for monitoring is the conceptual model for the site and the conceptual model for the contaminant and associated risk. In each case, the monitoring system should focus on the factors that demonstrate that the system is "in control" and the factors are causing the contaminant to behave as expected. In the case of metals and radionuclides, for example, many plumes are relatively stable and further migration of the contaminants is governed by the geo"Area Closure" strategies; and (2) application of statisti- chemical gradients. In this scenario, an effective moni- 
toring strategy would focus on documenting the status and evolution of the geochemical gradient over time.

The challenges faced by DOE in verifying the performance of EM actions are shared with the commercial nuclear industry, DoD installations, and chemical manufacturers and users. Thus, the proposed applied science developments in the EM program will be coordinated with the Nuclear Regulatory Commission, federal agencies (e.g., Environmental Protection Agency, U. S. Geological Survey, and DoD), state regulators and representatives such as the Interstate Technology and Regulatory Council, and stakeholder groups. This is particularly important for challenging scenarios such as on where centuries

The following are specific examples of the general direction and topics currently identified in the DOE-EM applied science needs portfolio:

- Develop and apply approaches to validate performance of active remediation, isolation, or natur-

attenuation strategies over long timeframes.

- Increase use of integrating measurements (e.g., one tool in addressing heterogeneity.

- Optimize LTM strategies [i.e., what, where, how - often, how accurate, and how expensive to measir and with what sensor(s)]. Encourage appropriate use of screening techniques and field methods to reduce overall costs.

- Expand LTM beyond traditional monitoring wells. This includes ecosystem monitoring, biomarkers biological monitoring, and boundary condition monitoring (i.e., weather, steamlow, evc piration, etc.).

- Build tracers, markers and/or engineered feature into remediation systems to provide direct meaEncourage the development and application of rogates and indicator parameters.

- Develop approaches and durable sensors for measuring contaminant concentrations, key processes/ transformations, or relevant proxies over field relevant scales.
- Improve cybersystem to provide a current or support a future living database for data storage and
visualization that is integrated with analysis tools

- Formalize protocols to revise conceptual/numerical models and to refine remedial approaches based on information provided by LTM datasets.

The key to closing and transitioning a waste site into an LTM program will rely on the confidence that the regulators and stakeholders have in the remedy or containment system. This confidence will be built on having a predictive capability of the long-term effects, identifcation of fallure indicators and a reliable order to develop a cost-effective system, the monitoring of failure indicators must be gathered by passive imple field screenis be highly automated or rapid and low cost. They must screen for changed conditions in a manner that is easy to understand and present. The information must be made available at a central location for further analysis and archive. A high degree of automation can be achieved through the synergistic combination of sensors for measurements and periodic multidimensional measurements to provide information between the measurement points. The design of an LTM system should enhance confidence in the system being monitored. Stakeholders and regulators need authenticated and scientifically-defensible information that remedial actions ensure the safety of future generations. Gathering, archiving, analyzing and most importantly, openly distributing information, builds trust.

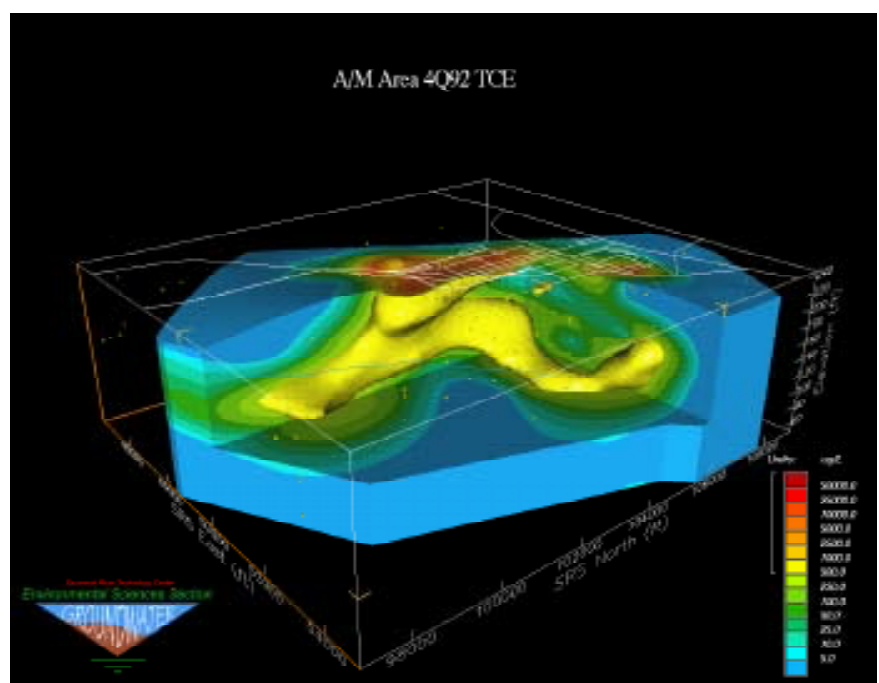

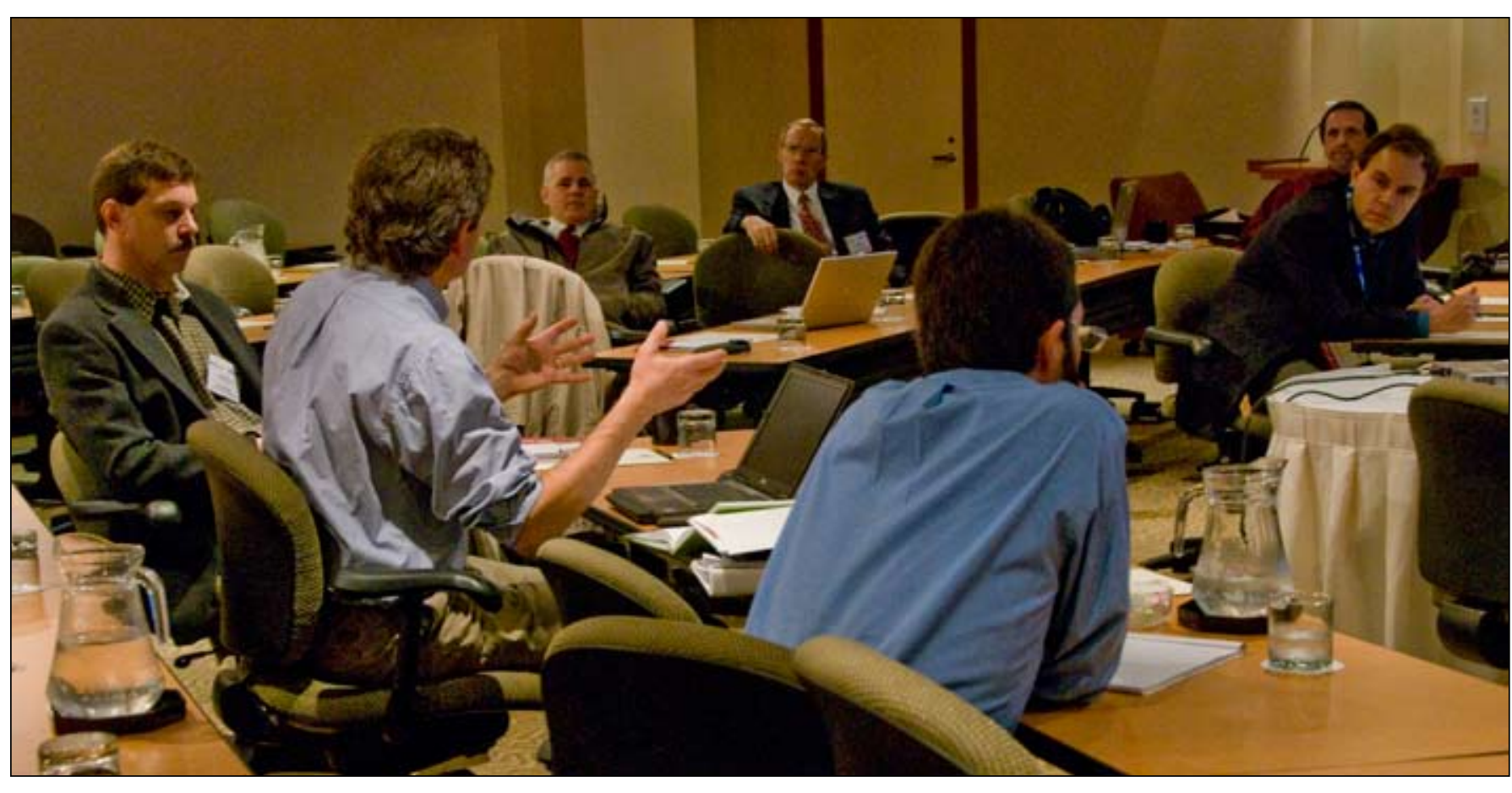

The results of the three LTM Breakout Sessions, (1) Performance Measurement Tools, (2) Systems, and (3) Information Management, are summarized in the following sections. The participants in the Breakout Ses-
sions were provided with the following guidelines:

- Consider successful monitoring efforts employed n related fields (e.g., agriculture, oceans/ fisheries, fires, hurricanes, etc.) and in other agencies and organizations (e.g., NASA, USDA, NOAA, EPA USGS, etc.)

- Try to expand discussion beyond current paradigms

- Consider new and alternative concepts to serve as the basis for monitoring system design (e.g., mobile versus "immobile," contaminants that are c);

...); - Overall, remer the unique challenges faced by LTM systems (e $g$, as noted by Paul Johnson by describing subsurface monitoring. "It's dark down there").
The participants in the Breakout Sessions were also sked to:

- Identify traditional approaches, alternatives and emerging ideas within topic;

- Tabulate strengths and weaknesses and synergies;

- Identify 2 to 3 investment sectors (i.e., initiatives) within each topic; and

- Identify issues for other teams (share and discuss as needed).

\section{LTM Performance Measurement Tools}

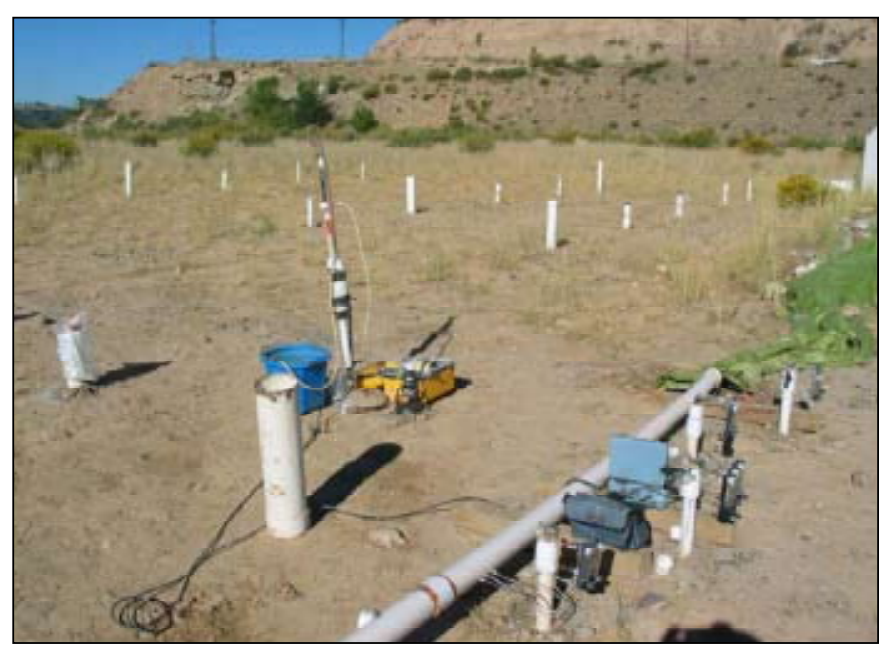




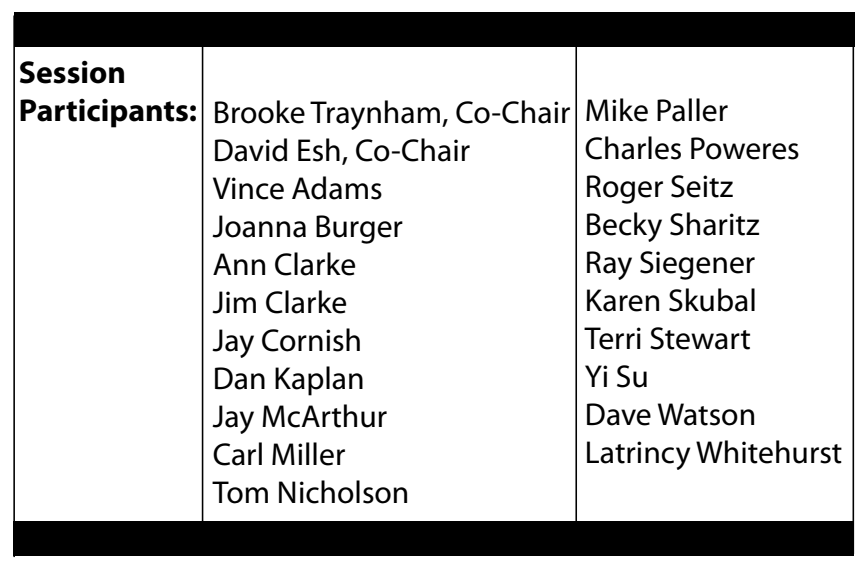

The focus of the first Breakout Session, LTM performance measurement tools, was on the integration and improvement of LTM performance measurement and systems, boundary conditions, geophysics, remote sensing biomarkers, ecological indicators and other types of ing, biomarkers, ecological indicators and other types of data used in LTM configurations. The Breakout Sessio and a broad variety of technical disciplines. The goal of the session was to identify alternatives or options for improving the existing LTM paradigm with respect to the performance measurement tools employed or envisioned. Initially, the session included presentations and discussion on system level concepts in order to provide context for presentations and discussion on individual tools and technologies. The attendees agreed that selection of monitoring tools should be based on mitigating technical and decision risk. In order to effectively do this, initially some form of analysis must be performe to identify key monitoring areas and associated indicators. Attendees also agreed that the process should be iterative, such that monitoring observations can be used to improve analyses and could, in theory, result in changes of focus or direction to the overall monitoring program. Without changes to regulatory requirements, be impeded.

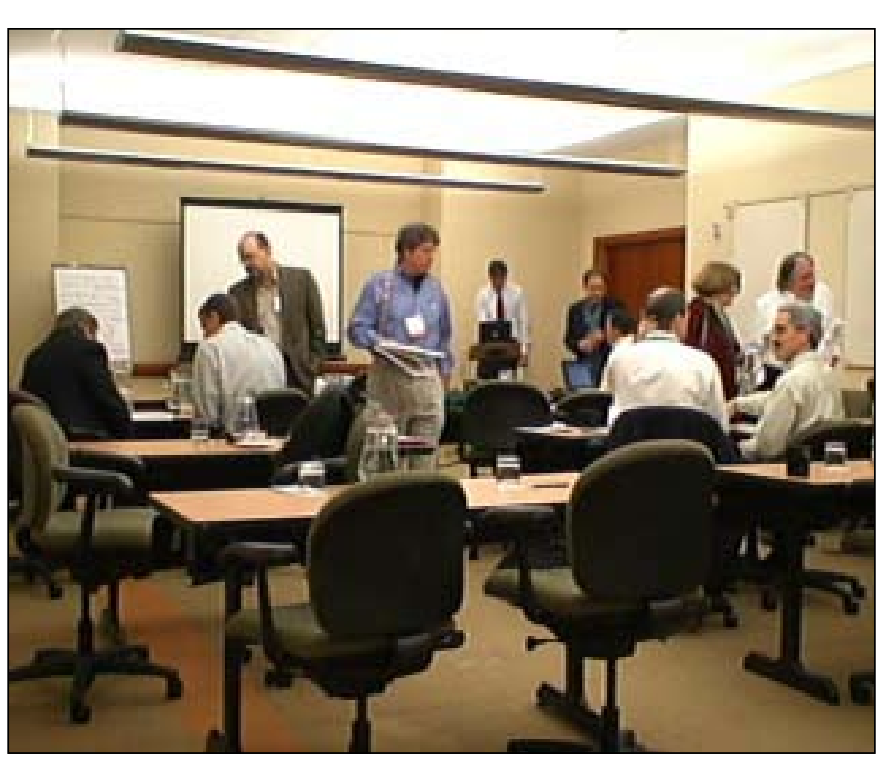

Indicators should focus on those items that can mitigate decision risk and are of most concern to key stakeholders. In order to be most effective at achieving these goals, the LTM process should optimize the selection of indicators and associated tools because the optimum and decision and not locally for a particular component or process. The indicators should be leading, provide early warning of unanticipated changes to system conditions, and at appropriate temporal and spatial scales. LTM tools should have as many of the following characteristics as possible:

Be remote, robust, durable, non-intrusive, and costeffective;

- Cover appropriate spatial scales;

- Aggregate properties; an

with stakeholder concern

The Breakout Session included a variety of presentations on particular tools and technologies (see attached CD). The presenters and attendees were asked to con-

- Can the tool be applied remotely?

- What scale does the tool address (temporally and spatially)?

- What properties does it measure? (indicators)

- If it uses embedded sensors, how long will they

last? How durable is the tool?

- How labor intensive is the collection of information?

- What resolution does the technique have?
- Does it provide a measure of performance or an inference of performance?

Although specific tools were discussed, it was recognized that the Breakout Session could not comprehensively discuss all monitoring technologies in the time provided. Attendees provided key references where other organizations have assessed monitoring tools (e.g., Burger 2006, Burger and Gochfeld 2001, Ho et al. 2004, Malusis and Benson 2006, Versteeg and Johnson 2008)

For organizational purposes, tools are grouped into two general categories: traditional and remote sensing. Traditional monitoring tools have a longer track record of use than remote sensing tools and provide direct ever, trolition to the gre: (1) limited in their. lowdurability, subjective to impacts that may comp-term equipment integrity and (2) labor intensive. Tradition monitoring tools have historically been used for both urfe and subsurace processes including ecological, hydrological, and structural components. Remote sensing technologies (e g. satellite imagery, Lidar) have potential to serve as a vital component in an LTM toolbox by collecting regular data over large areas, for long periods of time. An area of key interest is in coupling remote sensing technology with high-resolution ground sensors.

Sensors may be useful to measure hydrological compotry. Sensors can be used in networks to cover large are and can be integrated with "smart" chips to assist in data management/filtering. The relevancy of subsurface sensors is determined by the extent to which the subsurface processes of interest affect the properties sensed by the sensor. Incorporating sensor technologies into LTM plans is inhibited by the nature of sensors to break easly, have high costs, and lack environmental sensitivity.

Ecological monitoring tools include sensors; however, this type of tool also should include bioindicators. Biointerse limited in their ability to serve as leading indicaty and represent an indirect measurement of the system.
LTM Performance Measurement Tools Investment Sectors

The investment sectors developed in the LTM Performance Measurement Tools Breakout Session included the following:

- Surface Techniques - Improvement of surface emote sensing and non-invasive techniques (e.g. fanslating biotic changes at the surface into identifying subsurface changes)

- Subsurface Techniques - Development of techniques to remotely and non-invasively provide subsurface hydrology, chemistry, and structural conditions.

( as leading and long-term indicators.

\section{LTM Systems}

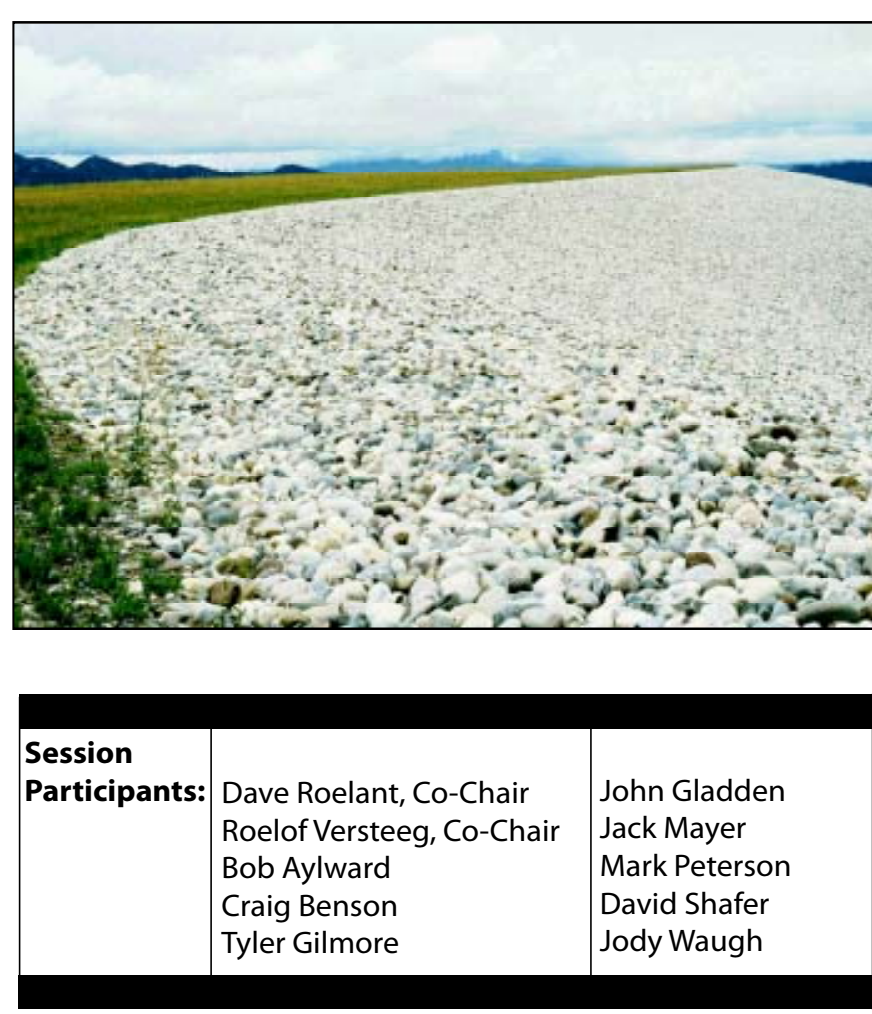

The second Breakout Session was on LTM systems. The objective of the LTM systems workgroup was to provide a vision and path towards novel and innovative actionable information on system performance in a cost-effective manner. More specifically, this group both discussed the current state of-the-art of LTM systems, as 
well as approaches, paradigms and frameworks associated with novel systems. This session was attended by 10 participants representing a variety of organization and backgrounds.

LTM System Definition and Scope - An LTM system (LTMS) is defined as the combination of elements which provide regulatory compliance and system performance information on contaminated sites or locatio to regulators and stakeholders. Elements of a LTMS typically include:

- Sensors and supporting infrastructure used for data collection;

- Enabling cyberinfrastructure (data management,

analysis and visualization tools, reporting tools);

use of conceptual and numerical models); ang

- Reporting.

Within DOE, LTMSs typically will be used for four different types of contaminated systems:

- Caps and covers (i.e., engineered systems),

- Highly concentrated source zones (e.g., ponds,

bldg structure left, cribs, USTs, etc.),

- Engineered remediation systems (e.g., enhanced

attenuation, PRBs), and

- Large "diffuse" contaminated sites.

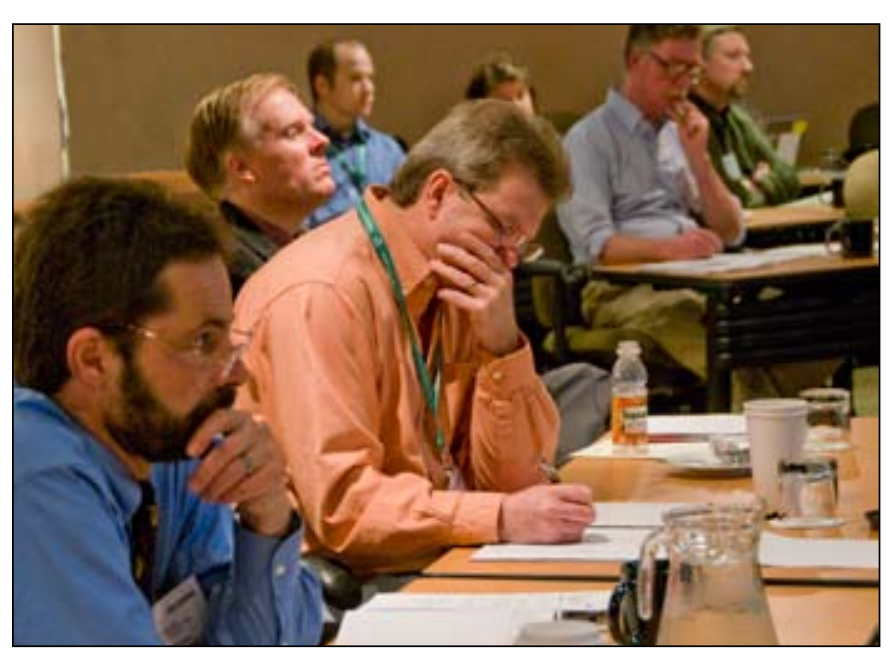

Each of these systems (and each specific instance of these systems) has unique attributes and risks associcustomized to a specific site. However, it is the feeling of the working group that the underlying paradigms and approaches to LTMS are for a large part identical for all systems.

State of the Art - The state of the art described here represents a consensus high-level view of the Technical Forum attendees of what is currently occurring at ongoing DOE LTM sites.

Current LTMS efforts typically consist of point measurements that are compliance driven, followed by reporting of the results of these point measurements in a graph or table format to regulators and stake holders with this being accomplished through a negotiation with this being accomplished

Current LTMS efforts typically do not include:

- Use of decision support tools, risk and site con- Ustual models to inform design and operation of LTMSs;

- Prediction of system behavior in the short and long term through either analog sites, conceptual or numerical models and/or use of data to provide improvement to models of the system;

- Data collection or analysis focused on quantifying or understanding overall system performance (including that caused by sporadic high impact events); and

- Incorporation of the effect of the natural ecosystem (watershed, area of influence around sources, etc.) on the contaminated system.

Ideal LTMS Attributes - The consensus by the Technical Forum attendees was that by focusing on regulatory compliance monitoring (and not including any of the items listed above), LTMSs are substantially less efficient than they should and could be. In addition, the cost/benefit ratio of LTMS is less than what is possible. The discussion about what was missing from current ystems led to the development (at the Technical Forum) is given in Appendix $C$ of this report for the reader to consult. Note that there is significant overlap between some of these attributes. While minimal editing of this list was done for clarity and to remove duplications after the Technical Forum, the objective of presenting this list here "as is" is to communicate the range of different ideas.
Based on this list of ideal LTMS attributes and a discussion among the attendees, the Breakout Session came to the conclusion that an LTMS paradigm shift is needed. Consequently, the group laid out a path toward new LTMS.

LTMS Novel Paradigms - The attendees concluded that novel paradigms are needed in the design and operation of LTMSs. Specifically, future LTMSs should

- Shift from compliance monitoring to whole system (i.e., watershed, disposal facility + ecosystem) performance monitoring;

- Move to a risk-based decision process for entire LTM system; and

Actively use decision support tools, risk and site conceptual models to inform the design and operation of LTMS.

Path Forward for Developing Next Generation LTMS and Associated Investment Areas - It is clear that translating the novel paradigms listed above into a in Appendix $\mathrm{C}$ will be challenging for several reasons, including but not limited to regulatory acceptance, potential initially higher cost, lack of tools, and buy in from the applicable DOE-EM operations or field office. In addition, achieving a system which has all of the attributes identified by the Technical Forum participants in the first iteration will be impossible.

Thus, a path forward is envisioned in which DOE-EM would focus on two investment areas. One should note

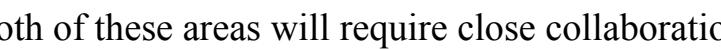
with regulators and stakeholders.

\section{LTM Systems Investment Sectors}

The two investment sectors developed in the LTM Systems Breakout Session included the following:

- Compliance to Performance - The objective of investment area would be to field demonstrate the driven monitoring to performance monitoing. This likely would occur on an active or new ITMS. Within this area several objectives could be pursued simultaneously, for instance, demonstrate the ability to refine long-term remedy system performance monitoring iteratively, evaluate the accuracy and validity of different monitoring and predictive tools, and develop integration between risk and performance models.

Point to Landscape Measurement - The objective of this investment area would be to field demonstrate the benefit and feasibility of a shift from point measurements to landscape scale measurements. This likely would occur on an active TTMS. For example, research in this area could include how macroscopically observable ecological parameters can be used as leading indicators of system performance, how such parameters are related to smaller scale observations, and how natura ed to predict long-term system performance.

\section{LTM Information Management}
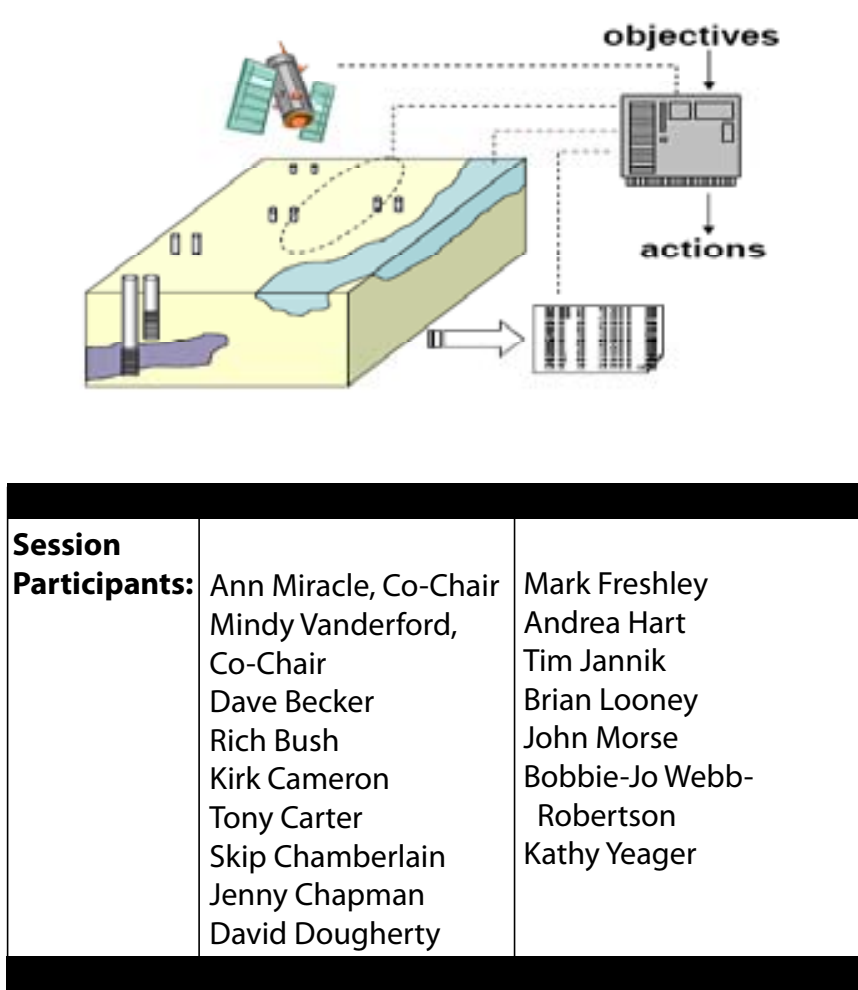

The third Breakout Session of the Technical Forum was was on the development and imp. The sation of novel information management systems for LTM including techniques to address data issues such as: efficient management of large and diverse datasets; consistency and comparability in data management and incorporation of accurate historical information; data interpretation and information synthesis including statistical methods, modeling, and visualization; and linkage of data to site 
management objectives and leveraging information to forge consensus among stakeholders. The informatio

The goal of information management is to collect, organize, analyze, archive, and communicate information to serve diverse populations over the long term. Effective information management is central to the task of long-term environmental care of DOE sites. Long-term environmental monitoring data are required to confirm the protectiveness of environmental remedies, evaluate ecosystem restoration and provide assurance of $s$ conditions for human and ecological communities.

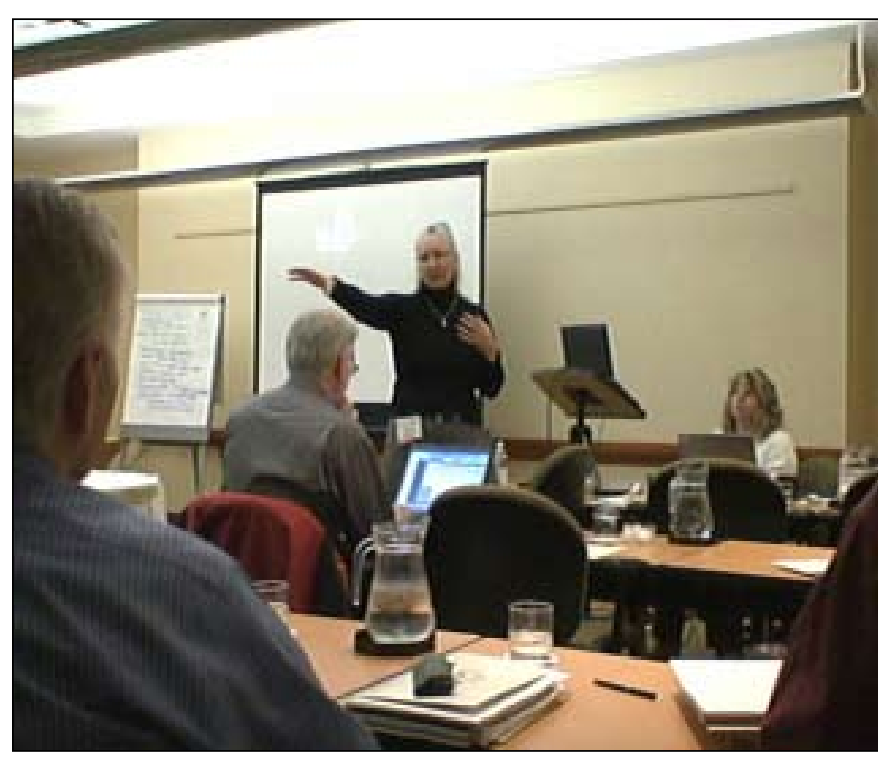

The Information Management Forum (IM) Breakout Session was convened to provide suggestions for the development and implementation of efficient information management systems for LTM across the DOE complex
The IM Breakout Session topics include approaches and techniques to address issues such as:

- Efficient management of large and diverse datasets Consistency and comparability in data handling ion;

Accessibility of

- Data interpretation and information synthesis including statistical methods, modeling, and visualization; and

- Linkage of data to site management objectives and leveraging information to forge consensus among
Environmental information management challenges at DOE center around communication between and within agencies in transition, and effective technology transfer for sites entering LTM. The program faces challenges establishing database systems that can accommodate arge quantities of diverse data in evolving formats. Additional challenges include providing useful user interfaces and analysis options to distill monitoring output to a level that can be interpreted by and communicated to stakeholders easily. Tools to analyze and distill data must be flexible enough to adapt to change in data input and evolving environmental support objectives. A five-year vision for addressing these challenges seeks to leverage existing cyber-infrastructure, provide guidance for addressing management and communicafor integrating environmental operations.

The IM Breakout Session has identified six major categories of challenges presented by current environmental information management practices at DOE. These are discussed in the following paragraphs:

Relevancy of data: Effective environmental management decisions are supported by the right type and quantity of data delivered in a timely fashion. Currently, environmental data collection is driven by regulatory compliance, management inertia or a "one-size-fits-all" approach and often, is not tied to specific management objectives. Several types of inefficiencies result from failure to 'right-size' data collection. Too much unstructured data can overwhelm decision-makers and divert focus from important issues. Too little of the right type of data can cause decisions to be made without adequate support or confidence. Data are not collected in a vacuum, and ancillary, supporting information relevant to a method or to the site is often not preserved. Missing details of how the data were collected can make interpretation and comparison of data over time extremely difficult. Historically, data have been condensed into information has been lost redine, but critical support ness. Curation/Archiving: Data must be maintained in a
way that preserves the integrity of the data while still way that preseriges the integrity of the data while still search and retrieval. Data storage formats regularly evolve over time and become obsolete. Simultaneously, routine data collection generates larger and larger quantities of data to be stored, and new types of data from advanced monitoring tools enter the data managemen system. Problems of digital curation as well as historic archiving are common across environmental management programs, but the scale of the dilemma at DOE particularly daunting. With different contractors presen at different labs and sites across the DOE complex, there are different data storage systems, different database and formats, and different levels of data maintenance. Some data stored with consultants can be lost to the complex if measures are not taken to secure and maintain that data. Currently, there is a lack of consistency in how environmental data are stored and maintain Data from historic monitoring programs may lack reference information that is critical to integrating it with new data to provide a long view of environment processes. Additing the the that current sites do not have the funding to address. Archived data are often not readily available and are in a usable format for long-term preservation. Poorly archived data may be vulnerable, as there is no redundancy in the system. In some cases, the environduntal history of many sites may be lost forever in single disaster event.

Accessibility: Critical data from environmental management programs should be available to project managers, contractors and stakeholders to the extent that the information does not pose a security risk. An efficient long-term environmental management program is dependent on timely access to data and tools to interpret that data. Many factors currently restrict broad access to data that may support site management decisions. Some of factors related to curation and archiving of data are discussed above. In addition, security issues often prevent easy access for site contractors to deposit or retrieve information related to monitoring. While some DOE sites may not have security restrictions preventing easy access to monitoring information, there are sites where this challenge that will need to be addressed if a paradigm shift for LTM is to be realized. In data project me nan hould be able tom complex-wide cess prfortion on their own projects, but should acbe able to access information from similar sites across the complex. By sharing how certain environmental conditions are described or regulated at other locations, project manegers may have better tools to macations, own sites. Currently, access to information is designed for human eyes, but systems should be put in place so that content can be evaluated automatically by software in order to streamline access to relevant data.
Quality Assurance: Environmental management decisions are only as good as the quality of data supporting them. Data quality is integral to reducing uncertainty around performance of remedies as well as containment technologies at closed sites. High quality data are those data that are fit to support site management decisions on cure the site. Quality data have sufficient supporting information to assess the completeness, validity, consistency, precision, comparability and accuracy of the dataset. For example, supporting documentation for tools and technologies used to gather the data should accompany the primary data. Supporting information would sho instrumentation calibration, data validation, or certified post-processing of raw data. These supporting files with accessible links provided from the data souro files.

Integration: Evaluation of long-term environmental restoration requires a complex and diverse dataset in order to develop a 'ines-of-evidence' formulation to support management decisions. The complexity of data required under performance-based monitoring will necessitate integration of data in a cost-friendly and timely manner. Integration of complex datasets will be necessary to move from single, point source monitoring technologies to multiple point and non-point source tools. The DOE requires integrated tools for assessing and predicting change in the environment at spatial and temporal scales across a variety of measurable processes and endpoints. As the paradigm shift moves LTM from compliance-based to process and performance-based, an understanding of how different types of data are required to becomes necessary. Integrated datasets are signed to predict effectiveness of technologies deal health. Multiple sources of information, environmenassembing vide a near real-time status of the site goes a lor to proIntegration extends to methods and tools to analyze and visualize data, including software products and models.

Communication: In order for data to become information, it must be processed and structured within a given cation, it must be heard. Communication is the essential final step in long-term environmental information management. Effective risk communication ensures that all parties involved in long-term environmental restoration have equal information for making decisions. Effective 
communication is necessary to be able to demonstrate to stakeholders, special interest groups, and the public, that LTM data provide assurances that human and environmental health are protected. The products of integrated data and information management should be readily interpretable for decision makers, and should match the objectives of LTM of the site. Communication at the finer levels of data and information resolution is also important for maintaining an active dialog within the research community to ensure transfer of ideas, approaches, and successes within the DOE complex.

\section{LTM Information Management Investment Sector}

In order to address the challenges of data management for LTM decision-support and to lay the foundation for ment sectors have been identified:

- Identify and build on existing information infrastructures;

- Review and revise governing DOE orders related to information management;

- Develop a distributed data search engine with comprehensive coverage of DOE complex environmental information and relevant sources outside of DOE (e.g., EPA, NOAA, NASA, etc.). Data and content from the network should be processed fo review and the analysis of resources.

\section{Build on Existing Information Infrastructures}

The DOE is one of the largest data generating entities in the world. In addition to the substantial amount of environmental management data generated by the complex, the DOE has historically had scientific and technological missions that would support future environmental and global sustainability research. DOE-EM requires an integrated environmental data management system where data resources composed of diverse formats from and made acessible to and programs can be archived

DOE currently has many data-management and webbased information storage and dissemination tools. However, the tools are widely distributed between locations and missions, and there is not one central clearinghouse for complex-wide environmental data. As part of the long-term IM survey, IM resources within DOE ferent systems for complex-wide information management should be identified. For example, DOE-LM uses an existing database structure, Geospatial Environmental Mapping System (GEMS), for real-time mapping of legacy sites with environmental monitoring data. Tools like GEMS should be identified and evaluated for their functionality and broad applicability.

Many of the information management challenges faced by DOE have been encountered and addressed by oth governmental agencies as well as the private secor. Entities such as the National Institutes of Health (NIH), National Aeronautics and Space Administration (NASA), National Oceanographic and Atmospheric Administration (NOAA), U. S. Geological Survey (USGS) ment of Defense (DoD) have significant data generation, archiving and retrieval issues. Many of these agencios have had to and retrieval issues. Many of these agencies

for managing large and diverse environmental datasets with modest budgets. Information management at has the added requirement of maintaining appropriate security of data. Outside of the public sector, private sector businesses have significant expertise in managing and linking data in secure environments. The DOE may consider interrogating other Agencies on the strengths and weaknesses of wide-scale data management sysems.

The IM Breakout Session recommends that DOE formally investigate solutions to large-scale, complex-wide environmental data management challenges by identifying high performing data management solutions that have been adopted by other agencies. A formal process would identify data management systems that contain:

- Large quantities of scientific data of diverse formats;

- Flexibility that can be modified to accept new data

Capabilities where data can be uploaded by a large number of distributed users;

- Capabilities where data can be retrieved by a large number of distributed users.

\section{Review and revise governing DOE orders related to} information management;

Contractor Standards: In order to address challenges generated for the DOE by outside contractors, govern- ing DOE orders should mandate delivery of all data in a format compatible with DOE information systems a appropriate points in the contracting cycle. In the past contractor incentives have not included the requirement to turn over all raw environmental data as well as all accompanying quality assurance/quality control and other supporting metadata in a consistent and timely fashion.

Requirements to relinquish datasets should be outlined explicitly in all contracts. Acceptable formats for fina datasets should be negotiated by the site managers, bu should retain minimum features outlined in a Data Stan-

Data Standards: The DOE should develop a complexwide guidance for minimum data collection and at chiving standards for all environmental or sustainability scriptive, but should lay the groundwork for developing a consistent data format, inclusive of significant metadata, in order to make the data useful for both curren and future decision-making. For example, specific supporting data requirements for certain types of molecular data must accompany submission of data generated for NIH studies, or for submission or publication in peerreviewed journals, and these requirements have been adopted world-wide as minimum information necessary to a Microarray Experiment (MIAME) guideline:

http://www.mged.org/Workgroups/MIAME/ miame_2.0.html).

Another example of this type of document may be the DoD Spatial Data Standards for Facilities Infrastructure and Environment:

http://www.sdsfie.org/WebTools/GlassBoxViewer/ abid/111/ctt/Privacy/Default.aspx.

Efforts such as the National Spatial Data Infrastructure (http://www.fgdc.gov/) are intended to coordinate and standardize data for spatial analyses.

Finally, while instituting a complex-wide security standard for environmental data may not be possible, declassified data should be identified and made available for project managers as efficiently as possible. Complex-
wide guidance on security issues for environmental data wide guidance on security issues for environmental data for inclusion in long-term data preservation systems.
Software standards: Software to be used for archiving, analysis or visualization of DOE EM data should be able to accept data in a consistent format. New software tools and purchase of tools should stipulate the format of input data, and that format should be consistent with the data standards described above. Emphasis should be placed on appropriate software currently available an on open-source software that can be modified to integrate various types of environmental data.

Develop a distributed data search engine with comprehensive coverage of DOE complex environmental information resources.

In order to address the challenges of access to information, integraton of resources, Hisk com IM Bation, dat Session recommends the development of a data search engine with comprehensive coverage of DOE complex environmental information as well as links to relevant exterior information sources. The development of a search engine would accompany a complex-wide effort to make both historic and current environmental data available in standard electronic format.

The DOEgle environment, a transparent, web-based system to provide access to relevant environmental data from complex-wide resources: The proposed system (with the working name of DOEgle) would employ traditional as well as the latest semantic web structure to provide a google-like search of DOE environmenta resources and relevant external resources. The search engine would be available to DOE environmental

managers and select consultants in order to streamline environmental decision making within the complex and provide an appropriate level of institutional memory to support long-term site care. Access to raw data maintained in a distributed network at DOE sites and server farms would be searchable through graded security prels as dictated by DOE mangement. The DOEgle provect we in the aforementioned recommendation). 


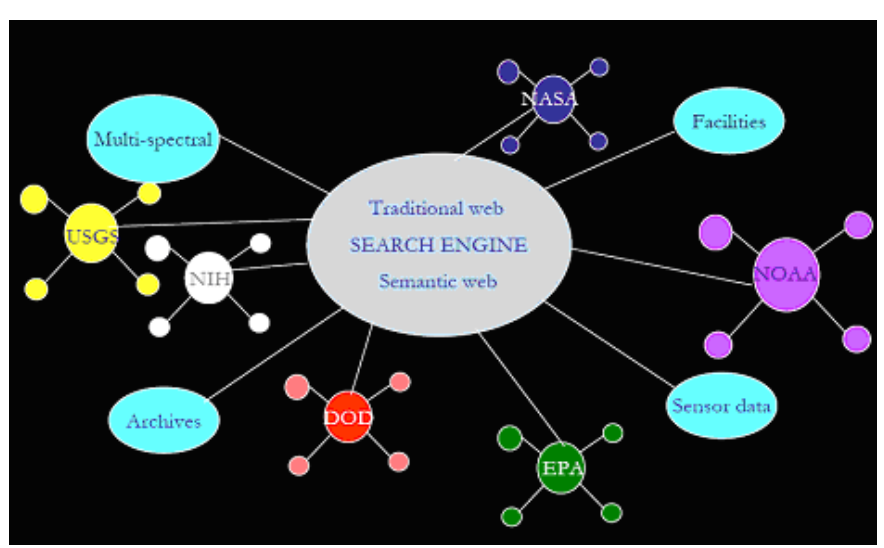

Figure 2. Illustration of the DOEgle system. Development of the DOEgle environment would be done by investing in structured layers. DOEgle would provide the user an access portal to search for site-speand tech transfer, supporting data, metadata, and anciland tech ermation sources. Environmental information is stored in a number of locations, from multiple programs, stored in a number of locations, from multiple programs,
and in a number of formats across the complex. Rather than transferring data to a central repository from the disparate sites and programs, the DOEgle portal would link to and query the distributed repositories.

DOEgle is conceived as an interface between localized data sources and final information products. DOEgle will access analysis widgets and models that can be used for data integration, analysis and visualization. Part of the project will be the development of middleware software that will automatically search and interrogate information sources, converting the raw data into a format that would feed into specialized widgets or applications. The middleware would provide the means to efficiently format data for common statistical analysis, visualization and communication applications. Communication of results can be further enhanced by development of 'results widgets' that produce easily interpretaaccess to the stapus of implementation tech a resource for communication of effective stewards to the public and stakeholders. DOEgle would query the network middleware would retrieve and transform the data and specialized widgets would compile the dat into information that can be conveyed to stakeholders.
By streamlining access to environmental data, the quality and efficiency of environmental decision making will improve and cost savings will be realized. Currently, lack of transparency and lapses in risk communicatio can undermine trust between citizens, regulators and the decision making process will elevate the level of trust between stakeholders and speed progress toward environmental management goals.

The DOE mission is to discover solutions to power and secure America's future. Environmental issues are central to the current energy, security, health and welfare concerns of Americans. These issues are best addressed through appropriate data collection, analysis, technology ing an envir a cientific and technogical missions that support environmental sustainability reseach would be achiever. By making information on environmental technologis available to scientific and technical communities, technologies can be enhanced and commercialized for the benefit of American industries.

The DOEgle environment represents a modest investment that would improve efficiency and credibility of federal programs and serve as a model for distributing other types of technology information from DOE in the future.

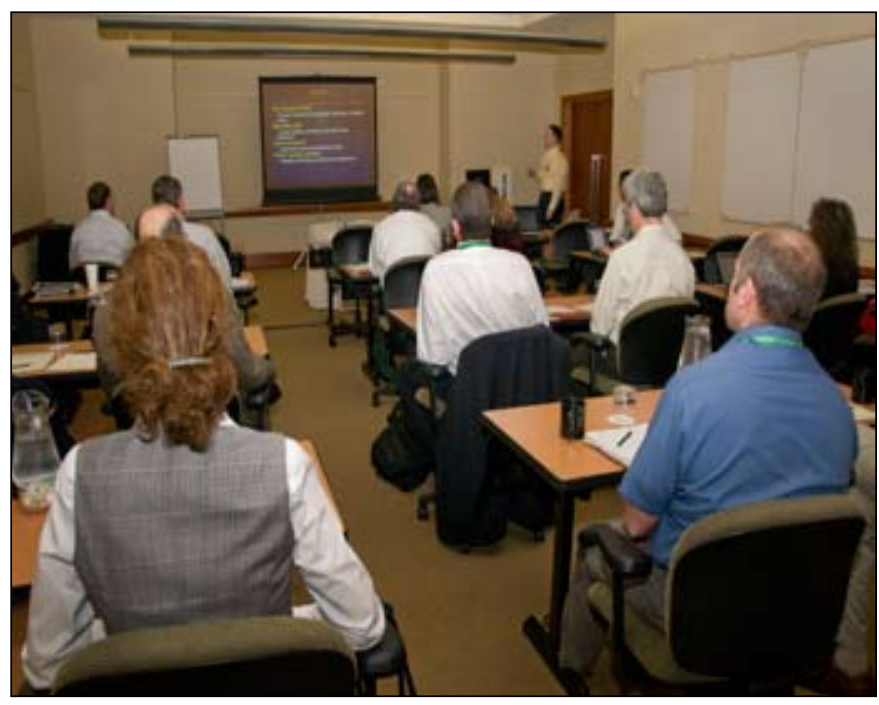

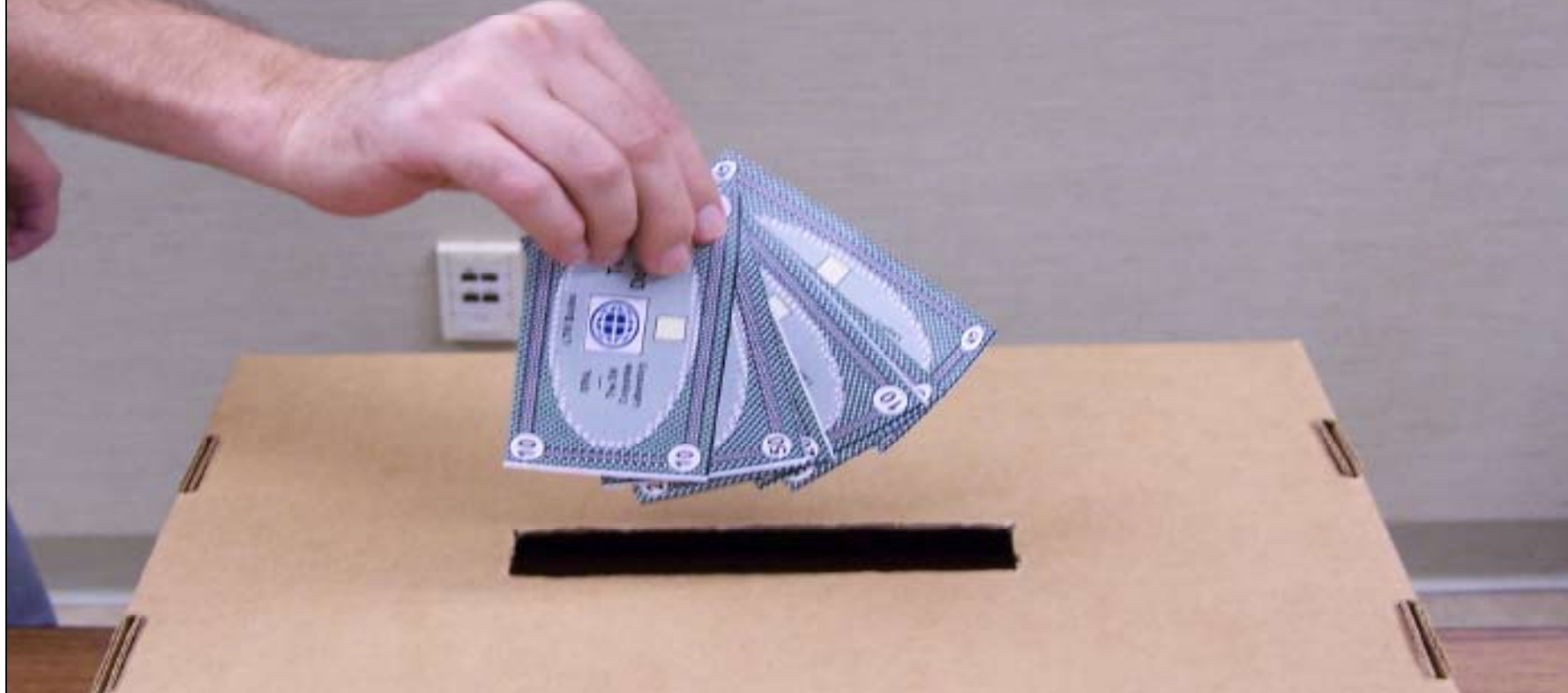

A major component toward improving the LTM paradigm is to identify areas in need of continued and future research. Those areas would ultimately be developed into the initiatives that would define and prioritize EM's LTM activities within the near-term 3-5 year time frame. Following the example developed for a previchallenges of the present Technical Forum was for the participants to identify and prioritize those near-term areas (i.e., investment sectors) to improve the current LTM paradigm. Those LTM thvestment sectors would then be used to develop the LTM initiatives.

This component of the Technical Forum was called the LTM Investment Sector Allocation Exercise. At regwas giv, each of 100 "LTM Bucks" (i. The to $\$ 5$, two $\$ 10$, one $\$ 20$ and one $\$ 50$ ). The participants aso comple a demoge a their background including the following: Affiliation - Government Academia Industry or Other; Focus - Government, Academia, Industry or Other; Focus tive, Regulatory, or Other; and Discipline - Geology/ Hydrology, Geophysics, Biology, Chemistry, Engineering, or Other. As part of their charge, each of the three Breakout Sessions was asked to identify between one and three priority near-term investment sectors within the focus area of that group (i.e., Performance Measurement Tools, Systems and Information Management). During the final Plenary session, the co-chairs from eac Breakout Session was asked to present and explain the group's investment sector(s). Following the investment sector presentations by the co-chairs, all of the partici-

www.em.doe.gov pants were then invited to invest their LTM Bucks into the choices provided.

\section{LTM Investment Sectors}

A total of six LTM investment sectors were identified by the three Breakout Sessions. By session, these included the following:

LTM Performance Measurement Tools -

Surface Techniques - Development/Improvement of remote sensing and non-invasive techniques for surface monitoring

Subsurface Techniques - Development/Improvement of remote sensing and non-invasive techniques for subsurface monitoring

Bioindicators - Development/Improvement of bioindicators as leading indicators for LTM LTM Systems

- Compliance to Performance

Point to Landscape Measurement

LTM Information Management -

- DOEgle Environmen

\section{Results}

A total of 46 of the Technical Forum's attendees participated in the LTM Investment Sector Allocation Exer- 
cise. The demographic profile of those participants is presented in Figure 3. Most participants were affiliated with the government $(67 \%)$, had a work focus on applied research (70\%), and were geologists/hydrologists by discipline $(33 \%)$. The majority of this latter category

A total of $\$ 4,600$ "LTM Bucks" were allocated into the six investment sectors. Individual allocations per a single investment sector ranged one person allocating their complin totals for the six single sector). The overall allocation totals for the six tive total allocation percentages by Breakout Session focus topic were as follows: Performance Measurement Tools $-44 \%$ (3 sectors); Systems - 29\% (2 sectors); an Information Management $-26 \%$ ( 1 sector)

The top four investment sectors include (in order of most to least): (1) the DOEgle Environment, (2) Subsurface techniques, (3) Compliance to Performance and (4) Bioindicators. Eighty percent of all resources were allocated among those four investment sectors.

Prioritization of the top four investment sectors varied by affiliation (Fig. 5). The government participants, again the largest group by affiliation, mirrored the overall investment totals from most to least. However, the academic affiliation group invested in the exact reverse of the government group, with Bioindicators as the top investment sector and the DOEgle Environment as the ally followed the government investment alloution, with the exception of the Compliance to Perforis sector being the lowest sector.

The work focus of the participants also resulted in a different percent resource allocation among the top four investment sectors compared to the collective totals (Fig. 6). The applied research focus also selected the DOEgle Environment as the highest investment sector, but, in contrast to the general totals, that was followed by the Compliance to Performance sector, and then closely by the Subsurface Techniques. Consistent with the academic affiliation, the basic research selected Bioindicators as the top investment sector; however, in this comparison, this was followed very closely by the DOEgle Environment. Both EM/Administrative and regulators favored the Subsurface Techniques investment sector, followed by the DOEgle Environment.

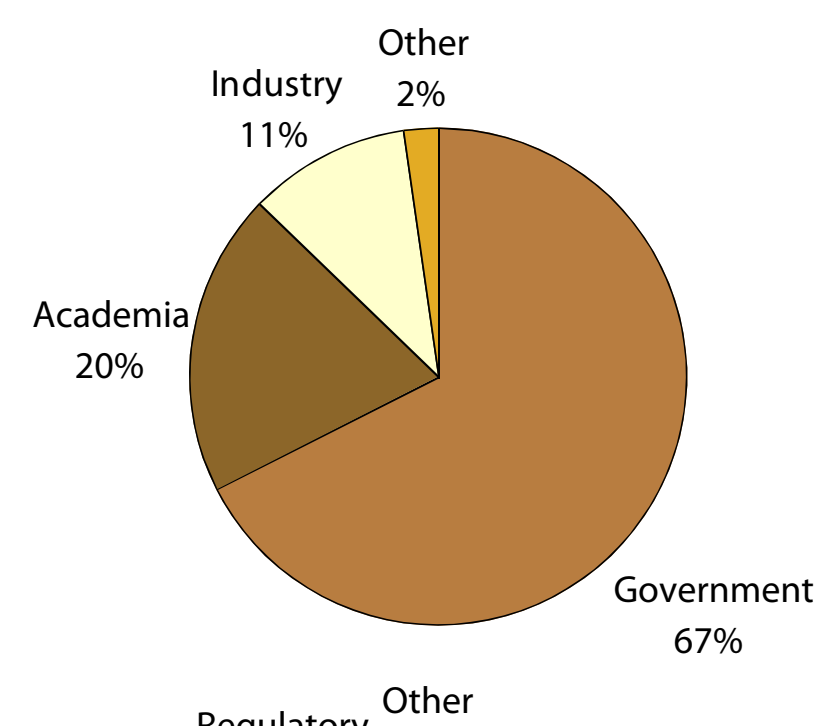

Regulatory

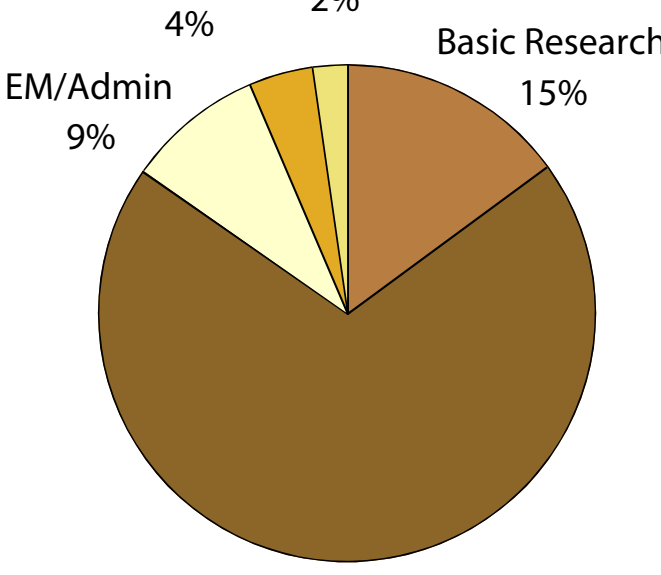

Applied Research

$70 \%$

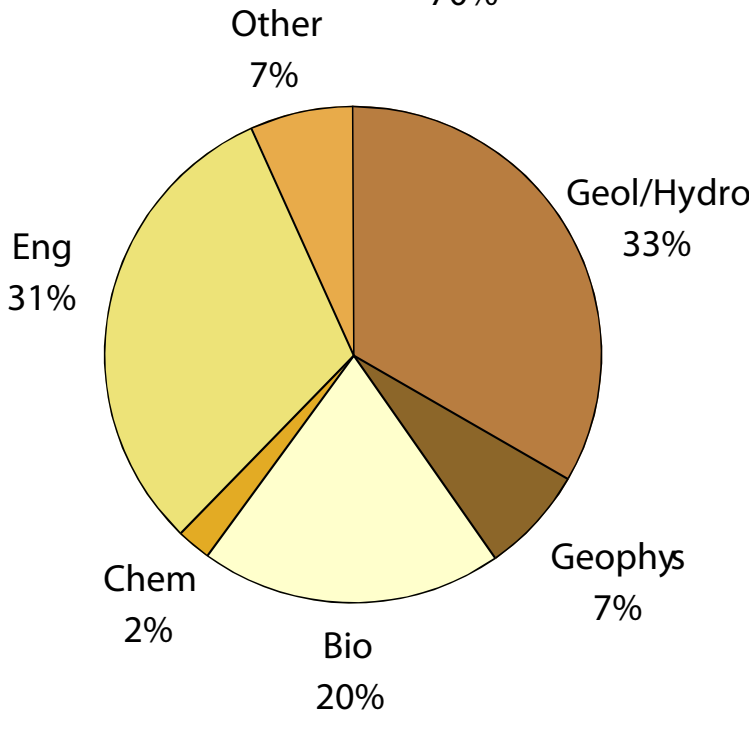

Figure 3. Demographic profile of the participants from the LTM Investment Sector Allocation Exercise.

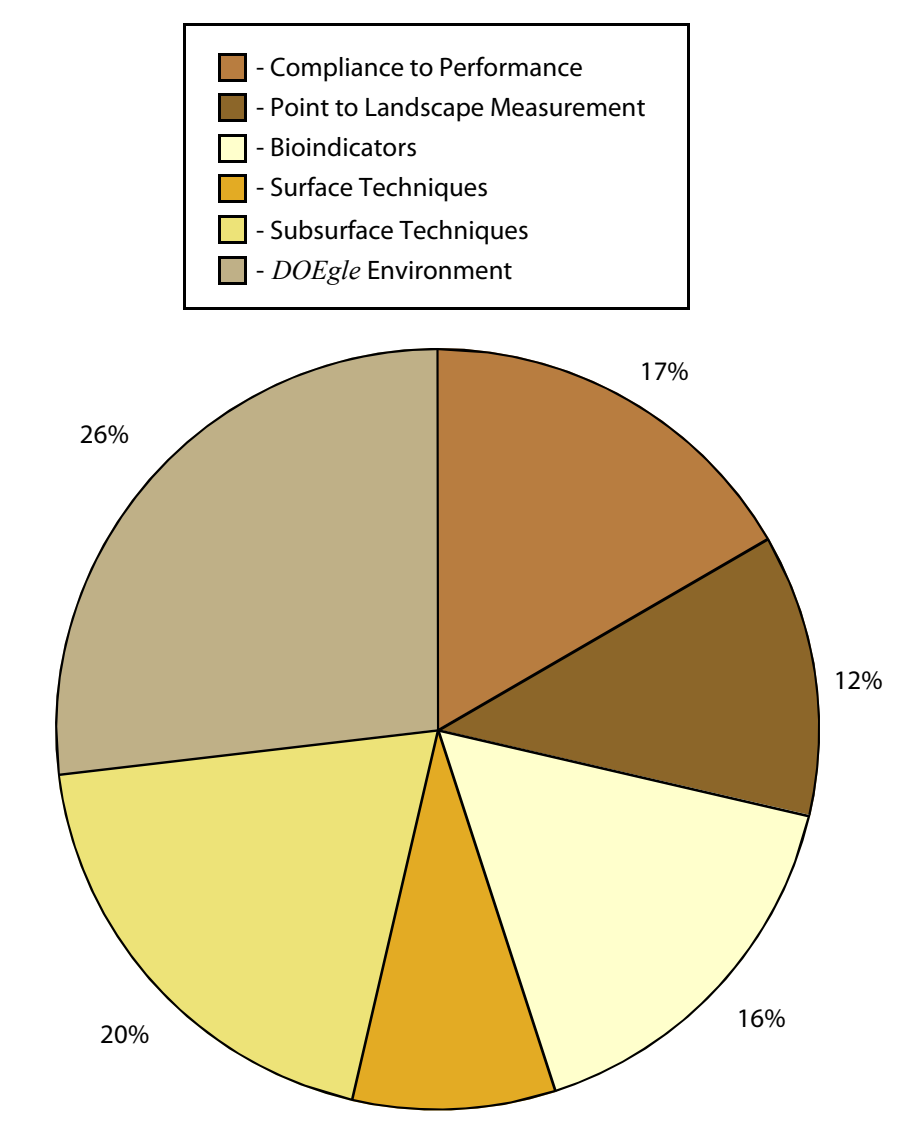

$9 \%$

Figure 4. Overall allocation totals for the six investment sectors.

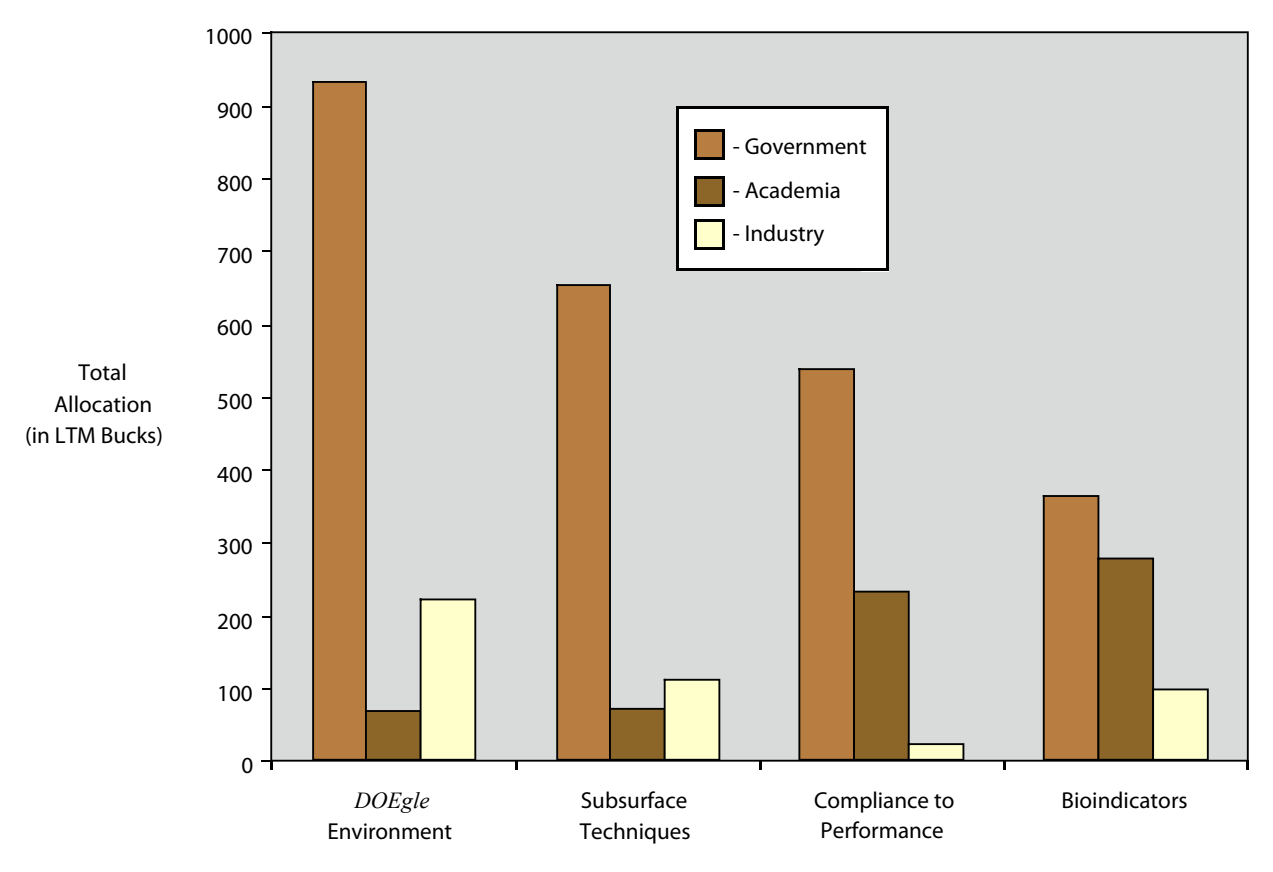

Minvestment Sector

Figure 5. Investment allocation into top four sectors by affiliation. 
With respect to the investment sector allocations based on the participant's professional discipline, again most of these varied from the overall allocation totals. The biologists strongly favored the investment into bioindicators. Chemists and geophysicists selected subsurface their top allocation the overall totals in their investment selections. Finally, the geologists hydrologists allocated their resoun into three closely ranked sectors, from Complimes Performance, then Subsurface Techniques, and finally the DOEgle Environment.

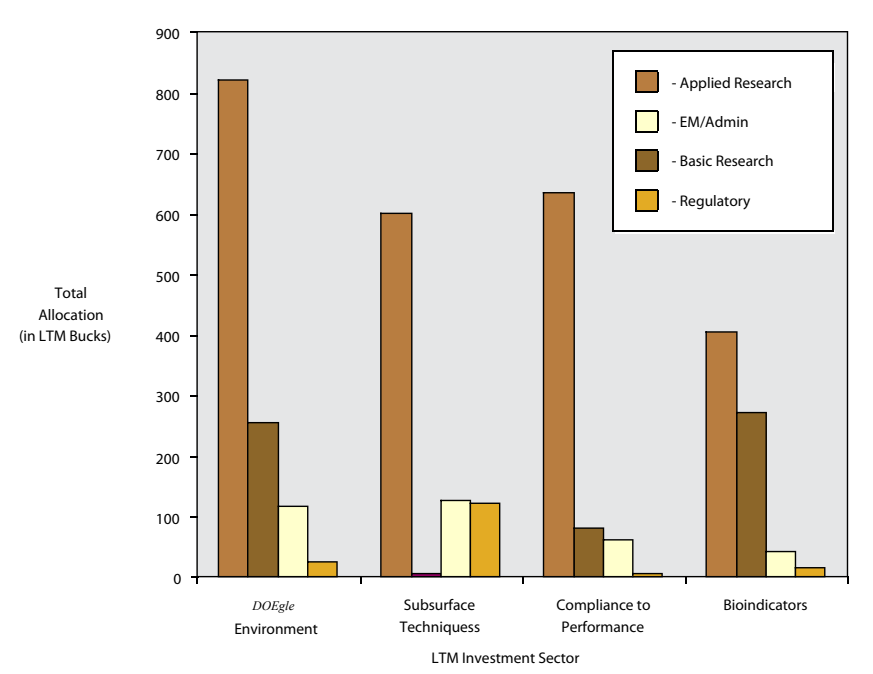

Figure 6. Investment allocation into top four sectors by work focus.

Although differences among the investment sectors did exist, this exercise did highlight a total of six priority

improving the LTM paradigm within the next 3-5 years.

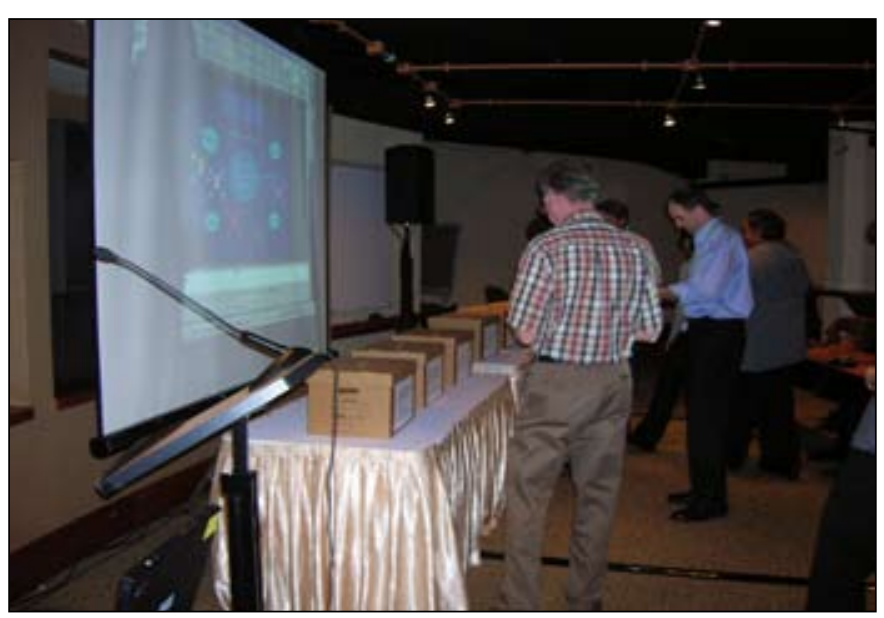

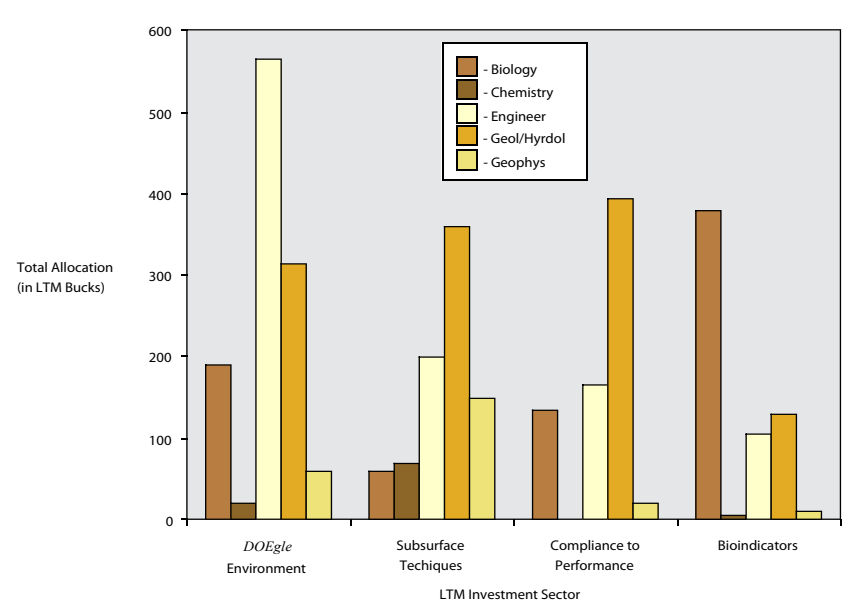

Figure 7. Investment allocation into top four sectors by discipline.

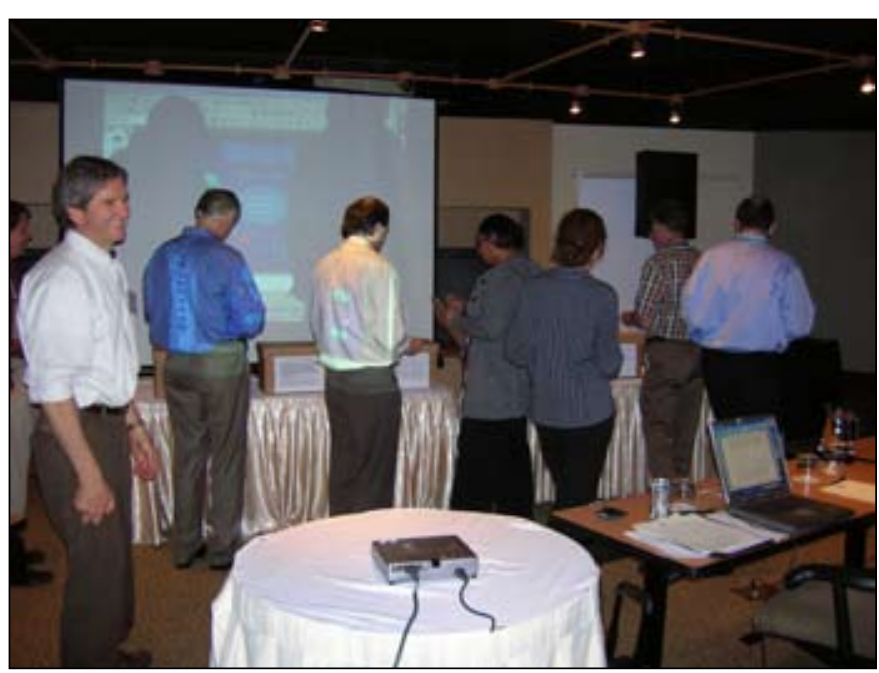

CONCLUSIONS AND SUMMARY OF RECOMMENDED

\section{INITIATIVES}

The fundamental objective in cleaning up and closing legacy waste sites is to achieve performance that will protect the surrounding environment with a long-term focus on health and human safety. LTM is key to verifying long-term performance with these engineered clo-

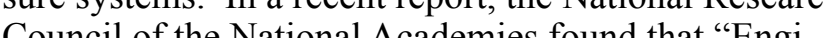
Coril of he have limited design lives comparithe time periods over which wastes will rempin hazardous and hence will require ongoing surveillance azd maintenance, and in some cases periodic replacentent to insure their continued ability to isolate wastes."

With respect to achieving successful clean up and closure of these DOE sites, the LTM paradigm needs to be improved. The participants in this Technical Forum concluded that to improve this paradigm, we must consider and, in some form, include the following:

- Employ the existing technology for affordable remote monitoring systems that employs sensors and remote sensing tools;

- Monitor containment system elements as well as the surrounding environment:

- Use monitoring systems for compliance monitoring, to validate designs, and to plan/create future strategy;

- Regulatory requirements must be changed in accordance with changes implemented within the LTM paradigm;

- Use design processes and systems that provide continuous assessment by coupling monitoring, design, and maintenance; and

- Learn from monitoring data to facilitate evolution of containment systems.

Toward addressing the reduction of the technical risks and uncertainties identified in the 2008 Roadmap, the participants at the 2009 LTM Technical Forum recommended five initiatives (Table 1). For each initiative, the anticipated outcomes and benefits have been described.

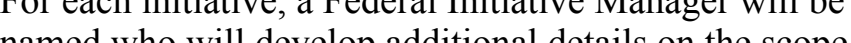
and schedule of the initive.

As stated in the 2008 Roadmap, focused, applied engineering and technology development has played a initiatives listed below are intended to contribute in that same function for near-term improvement of the LTM paradigm, and thus to ensure DOE's "success in paying off the mortgage of the Cold War - achieving the safe and compliant disposition of legacy wastes from defense nuclear applications."

Table 1. Listing of the LTM Paradigm Improvement Background Description, Initiative Details, and Outcome and Benefits.

\begin{tabular}{|c|c|c|}
\hline Background Description & Initiative Details & Outcome and Benefits \\
\hline \multicolumn{3}{|c|}{ Technical Focus Area: LTM Performance Measurement Tools } \\
\hline \multirow{2}{*}{$\begin{array}{l}\text { LTM tools should have as many of } \\
\text { the following characteristics as } \\
\text { possible: be remote, robust, durable, } \\
\text { non-intrusive, cover appropriate } \\
\text { spatial scales, aggregate properties, } \\
\text { align with stakeholder concerns, } \\
\text { and are cost-effective }\end{array}$} & $\begin{array}{l}\text { Improve surface remote sensing and } \\
\text { non-invasive techniques }\end{array}$ & $\begin{array}{l}\text { Implement more cost-effective } \\
\text { non-intrusive surface tools to } \\
\text { develop improved understanding } \\
\text { of long-term performance. }\end{array}$ \\
\hline & $\begin{array}{l}\text { Develop techniques to remotely and } \\
\text { non-invasively provide subsurface } \\
\text { hydrology, chemistry, and structural } \\
\text { conditions }\end{array}$ & $\begin{array}{l}\text { Implement more cost-effective } \\
\text { non-intrusive tools to develop } \\
\text { improved understanding of } \\
\text { subsurface long-term } \\
\text { performance. }\end{array}$ \\
\hline
\end{tabular}




\section{REFERENCES}

Table 1. Listing of the LTM Paradigm Improvement Background Description, Initiative Details, and Outcome a nd Benefits (Continued).

\begin{tabular}{|c|c|c|}
\hline Background Description & Initiative Details & Outcome and Benefits \\
\hline \multicolumn{3}{|c|}{ Technical Focus Area: LTM Information Management Tools (Continued) } \\
\hline $\begin{array}{l}\text { Ecological LTM tools should } \\
\text { include bioindicators, which are } \\
\text { temporally robust, measure } \\
\text { cumulative impacts, and have } \\
\text { relevance to stakeholders. } \\
\text { However, at present, bioindicators } \\
\text { are limited in their ability to serve } \\
\text { as leading indicators and represent } \\
\text { an indirect measurement of the } \\
\text { system } \\
\end{array}$ & $\begin{array}{l}\text { Improve/study bioindicators as } \\
\text { leading and long-term indicators }\end{array}$ & $\begin{array}{l}\text { Utilize bioindicators as advanced } \\
\text { indirect monitoring tools to } \\
\text { evaluate long-term performance of } \\
\text { the waste closure site within an } \\
\text { ecosystem perspective. }\end{array}$ \\
\hline $\begin{array}{l}\text { LTM systems need to move from } \\
\text { point measurement to entire } \\
\text { ecosystem monitoring with leading } \\
\text { indicators, bio-indicators, remote } \\
\text { sensing and other tools }\end{array}$ & $\begin{array}{l}\text { Develop, demonstrate and validate } \\
\text { an LTM Approach that transitions } \\
\text { from point measurements to } \\
\text { integrate landscape scale measures }\end{array}$ & $\begin{array}{l}\text { Improve the methods of increasing } \\
\text { the scale of LTM measurements } \\
\text { and the criteria that would be used } \\
\text { for leading indicators that would } \\
\text { integrate landscape scale measures } \\
\text { e.g., ecological parameters that } \\
\text { could serve as leading indicators } \\
\text { for remedy systems. }\end{array}$ \\
\hline \multicolumn{3}{|c|}{ Technical Focus Area: LTM Systems } \\
\hline $\begin{array}{l}\text { LTM systems need to shift from } \\
\text { compliance monitoring to natural } \\
\text { system (e.g., watershed, disposal } \\
\text { facility plus ecosystem) } \\
\text { performance monitoring of a } \\
\text { remedy system }\end{array}$ & $\begin{array}{l}\text { Field demonstrate a shift from } \\
\text { current compliance-driven LTM to } \\
\text { ones that provide the ability to refine } \\
\text { long-term remedy system } \\
\text { performance monitoring and to } \\
\text { evaluate the accuracy or validity of } \\
\text { predictive tools }\end{array}$ & $\begin{array}{l}\text { Refine long-term performance } \\
\text { monitoring to evaluate the } \\
\text { accuracy or validity of predictive } \\
\text { tools using a systematic review of } \\
\text { existing data for continuous LTM } \\
\text { improvement, periodic remedy } \\
\text { (e.g., 5-year remedy reviews), and } \\
\text { LTM performance model } \\
\text { validation/calibration. }\end{array}$ \\
\hline \multicolumn{3}{|c|}{ Technical Focus Area: LTM Information Management } \\
\hline $\begin{array}{l}\text { Identify and build on existing } \\
\text { information infrastructures }\end{array}$ & $\begin{array}{l}\text { Identify and build on existing } \\
\text { information infrastructures }\end{array}$ & $\begin{array}{l}\text { Identify and build on existing } \\
\text { information infrastructures }\end{array}$ \\
\hline $\begin{array}{l}\text { Review and revise governing DOE } \\
\text { orders related to information } \\
\text { management }\end{array}$ & $\begin{array}{c}\text { Review and revise governing DOE } \\
\text { orders related to information } \\
\text { management }\end{array}$ & $\begin{array}{c}\text { Review and revise governing DOE } \\
\text { orders related to information } \\
\text { management }\end{array}$ \\
\hline $\begin{array}{l}\text { Develop a distributed data search } \\
\text { engine with comprehensive } \\
\text { coverage of DOE complex } \\
\text { environmental information and } \\
\text { relevant sources outside of DOE }\end{array}$ & $\begin{array}{l}\text { Develop a distributed data search } \\
\text { engine with comprehensive coverage } \\
\text { of DOE complex environmental } \\
\text { information and relevant sources } \\
\text { outside of DOE }\end{array}$ & $\begin{array}{l}\text { Develop a distributed data search } \\
\text { engine with comprehensive } \\
\text { coverage of DOE complex } \\
\text { environmental information and } \\
\text { relevant sources outside of DOE }\end{array}$ \\
\hline
\end{tabular}

Burger, J. 2006. Bioindicators: A review of their use in ecological assessment and research. Environmental Bioindicators 1:22-39.

Burger, J. and M. Gochfeld. 2001. On developing bioindicator for human and ecological health. Environmental Monitoring and Assessment. 66:23-46.

DOE (U.S. Department of Energy). 2006. U.S. Department of Energy Strategic Plan. DOE/CF-0010. U.S. Department of Energy, Washington, DC.

DOE-EM (U.S. Department of Energy, Office of Environmental Management). 2008. Engineering \& Technology Roadmap. DOE, Office of Environmental Management, Washington, D.C.

Gochfeld, M., J. Burger, B. Friedlander, and C. Powers. 2007. Approaches for assessing hazards and risks to workers and the public from contaminated land. Remediation Journal, 18(1):29-57.

Ho, C. K., B. W. Arnold, J. R. Cochran, R. Y. Taira and M. A. Pelton. 2004. A probabilistic model and software tool for evaluating the long-term performance of landfill covers. Environmental Modelling \& Software, vol. 19, 63-88.

Looney, B. B. (ed.). 2002. Technical targets - A tool to support Strategic Planning in the Subsurface Contaminants Focus Area. WSRC-RP-2002-00077, Revision 0. Savannah River Technology Center, Westinghouse Savanna River Company, Aiken, SC

Malusis, M. A., and C. H. Benson. 2006. Lysimeters versus water-content sensors for performance monitoring of alternative earthen final covers. Geotechnical Special Publication, 1(147):741-752.

Moore, B., J. Ditmars, B. Minsker, and J. Bachmaier. 2001. Performance Evaluation Using Expert Elicitation and Long Term Environmental Monitoring Optimization for Long Term Stewardship. 4 pp. in 2001 International Containment \& Remediation Technology Conference and Exhibition, Orlando, Florida. http://www.containment. fsu.edu/cd/content/srch_f_t.htm (Accessed March 5, 2009).

NRC (National Research Council). 2000. Research Needs in Subsurface Science. The National Academies Press, Washington, D.C.

NRC (National Research Council). 2005a. Improving the Characterization and Treatment of Radioactive Wastes for the Department of Energy's Accelerated Site Cleanup Program. The National Academies Press, Washington, D.C.

NRC (National Research Council). 2005b. Risk and Decisions about Disposing of Transuranic and High Level Radioactive Waste. The National Academies Press, Washington, D.C.

Silbernagel, M., and J. Hafera. 2000. The vadose zone resource allocation challenge. Pp. 1444-1458. in B. B. Looney and R. W. Falta (Eds.). Vadose Zone Science and Technology Solutions. Vol. II. Batelle Press, Columbus, Ohio.

Versteeg, R., and T. Johnson. 2008. Using time-lapse electrical geophysics to monitor subsurface processes. The Leading Edge, 27(11):1488-1497. 
This page intentionally left blank

\section{APPENDIX A}

List of Participants

Contact Information 


\section{DOE-EM}

Long-Term Monitoring (LTM) Technical Forum

February 11-12, 2009

\section{List of Participants}

\section{Contact Information}

This page intentionally left blank

MSE Technology Applications, Inc.

679 Emory Valley Road

Oak Ridge, TN 37830

Phone: 865-220-8551

Fax: 865-483-6603

Email: tj.abraham@mse-ta.com

Dr. Vincent Adams

U.S. Department of Energy

Groundwater \& Soils Remedation

1000 Independence Avenue, SW

Washington, DC 2058

Phone: $301-903-1864$

Fax: 301-903-3617

Email: Vincent.Adams@em.doe.gov

Ms. Kaye Atkins

Savannah River Nuclear Solutions, LLC

Building 703-43A

Aiken, SC 29808

Phone: 803-725-88

Email: kay.atjubs@srs.gov

Mr. Robert "Bob" Aylward

Savannah River National Laboratory

Savannah River Site, Bldg. 773-42A

Aiken, SC 29808

Phone: (803)725-5190

Fax: (803)725-7673

Email: bob.aylward@srnl.doe.gov
Mr. Dave Becker

US Army Corps of Engineers

1616 Capitol Avenue, Suite 9200

Omaha, NE 68102-9200

Phone: 402-697-2655

Fax: 402-697-2613

Email: Dave.J.Becker@usace.army.mil

Dr. Craig H. Benson

University of Washington/CRESP/Vanderbilt Dept. of Civil \& Environmental Engineering 201 More Hall, Box 352700

Seattle, WA 98195-2700

Phone: 206-685-2658

Fax: 206-543-1543

Ms. Rosalind Blocker

Savannah River National Laboratory

EM Technical Integration Office

773-42A, Room 122

Phone: 803-725-7745

Fax: 803-725-8829

Email: rosalind.blocker@srnl.doe.gov

Dr. Joanna Burger
Rutgers University

Consortium for Risk Evaluation with Stakeholder Par-

ticipation (CRESP)

604 Allison Road

Piscataway, NJ 08854

Phone: 732-445-4318

Fax: $732-445-5870$

Email: burger@biology.rutgers.ed 
Mr. Richard Bush

US DOE Office of Legacy Management 2597 B 3/4 Road

Grand Junction, CO 81503

Phone: 970-248-6073

Email: Richard.Bush@1m.doe.gov

Dr. Kirk Cameron

MacStat Consulting, Ltd

Colorado Springs, CO 80908

Phone: (719) 532-0453

Email: kcmacstat@qwest.net

Mr. Tony Carter

U.S. Department of Energy (HQ/LM)

1000 Independence Avenue, SW

Room 6G-051

Washington, DC 20585

Phone: $202-586-33$

Fax: 202-586-1540

Email: tony.carter@hq.doe.gov

Mr. Grover "Skip" Chamberlain

U.S. Department of Energy

Office of Environmental Research, EM-22

1000 Independence Avenue, SW

Washington, DC 20585

Fax: 301-903-3351

Email: Grover-Chamberlain@em doe gov

Ms. Jenny Chapman

Desert Research Institute

755 East Flamingo Road

Phone: 702-862-5459

Fax: 702-862-5427

Email: jenny.chapman@dri.edu
Dr. Ann N. Clarke

7101 Executive Center Drive, Suite 187

Brentwood, TN 37027

Fax: 615-370-4090

Email: ancinc@edge.

Dr. James Clarke

Vanderbilt University/CRESP

School of Engineering

Nashville, TN 37235-1831

Phone: 615-322-3897

Fax: 615-322-3365

Email: james.h.clarke@vanderbilt.edu

Mr. Jay Cornish

MSE Technology Applications, Inc.

P.O. Box 4078

Butte, MT 59701

Phone: 406-494-7329

Fax: 406-494-7230

Email: jay.cornish@mse-ta.com

Dr. David E. Dougherty

Subterranean Research, Inc.

33 Enterprise Place, Suite 5

Duxbury, MA 02332

Pax: 641-795-0000

Email: ddougher@subterra.com

Dr. David Esh

U.S. Nuclear Regulatory Commission

11545 Rockville Pike

Rockville, MD 20852

Phone: 301-415-6705

Fax: 301-415-5390

Email: David.Esh@nrc.gov
Mr. Mark Freshley

Pacific Northwest National Laboratory

Post Office Box 999

Richland, WA 99354

Phone: 509-372-6094

Email: mark.freshley@pnl.gov

Mr. Tyler Gilmore

Pacific Northwest National Laboratory

P.O. Box 999, MSIN K6-96

Richland, WA 99352

Phone: 509-371-7171

Fax: 509-371-7174

Email: tyler.gilmore@pnl.gov

Dr. John B. Gladden

Savannah River National Laboratory

Building 773-42A

Aiken, SC 29808

Phone: 803-725-5215

Fax: 803-725-7673

Email: john.gladden@srnl.doe.gov

Ms. Andrea Hart

MSE Technology Applications, Inc.

P.O. Box 4078

Butte, MT 59701

Phone: 406-494-7410

Mr. Ron Hershey

Desert Research Institute

2215 Raggio Parkway

Phone: 775-673-7393

Fax: 775-673-7363

Email: ron.hershey@dri.edu
Mr. Tim Jannik

Savanah River National Laboratory

SRNL Building 773-42A

Aiken, SC 29808

Pax: 803-725-7673

Dr. Daniel Kaplan

Savanah River National Laboratory

Building 773-43A

Aiken, SC 29808

Phone: 803-725-2363

Fax: 803-725-4704

Email: daniel.kaplan@srnl.doe.gov

Dr. Brian B.Looney

Savannah River National Laboratory

Building 773-42A

Aiken, SC 29808

Phone: $803-725-3692$

Fax: 803-725-7673

Email: brian02.looney@srnl.doe.gov

Dr. John "Jack" Mayer

Savannah River National Laboratory

Savannah River Nuclear Solutions LLC

P. O. Box 616, Bldg. 773-42A

Aiken, SC 29808

Phone: (803) $725-5991$

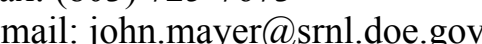

Dr. J. Vaun McArthur

Odum School of Ecology

Savannah River Ecology Lab

Drawer E

Email: mcarthur@srel.edu 
Dr. Carl Miller

MSE Technology Applications, Inc.

P.O. Box 4078

Butte, MT 59701

Phone: 406-494-7159

En: $406-494-7230$

Dr. Ann Miracle

Dr. Ann Miracle
Pacific Northwest National Laboratory
Post Office Box 999

Richland, WA 99352

Phone: 509-372-4327

Fax: 509-375-6936

Email: ann.miracle@pnl.gov

Mr. John G. Morse

U.S. DOE Richland Operations

P.O. Box 550, A5-11

Richland, WA 99352

Phone: 509-376-0057

Fax: 509-372-1926

Email: John_G_Morse@rl.gov

Dr. Thomas J. Nicholson

U.S. Nuclear Regulatory Commission

Office of Nuclear Regulatory Research

21 Church Street, Mail Stop CSB 2-A07

Rockville, MD 20850-4207

Phone: (301) 251-7498

Email: Thomas.Nicholson@nrc.gov

Dr. Michael Paller

Savannah River National Laboratory

Environmental Analysis Section

Building 773-42A

Aiken, SC 29808

Phone: 803-725-5250

Fax: 803-725-7673

Email: michael.paller@srnl.doe.gov
Mr. Mark J. Peterson

Environmental Sciences Division

O Box 2008

Oak Ridge, TN 37831-635

Pax: 865-576-9938

Email: petersonmj@ornl.gov

Dr. Charles W. Poweres

Dr. Charles W. Poweres

Consortium for Risk Evaluation with Stakeholder Par-

ticipation (CRESP)

303 Gorge Street, Suite 110
New Brunswick, NJ 08901

Phone: 732-579-1092

Fax: 732-579-1100

Email: cwpowers@cresp.org

Dr. David F. Roelant

Florida International University

7170 SW 103 Court Circle

Miami, FL 33173

Phone: $786-200-6220$

Fax: 305-348-1852

Email: roelantd@fiu.edu

Dr. Roger Seitz

Savannah River National Laboratory

Aiken, SC 29808

Aiken, SC 29808

Phone: (803) 7258269

Email: Roger.Seitz@srnl.doe.gov

Dr. David Shafer

Desert Research Institute

755 East Flamingo Road

Las Vegas, NV 89119

Phone: 702-862-5564

Fax: 702-862-5427

Email: david.shafer@dri.edu
Dr. Rebecca Sharitz

University of Georgia

Drawer E

Aiken, SC 29802

Phone: 803-725-5679

Email: sharitz@srel

Dr. Ray Siegener
GEI Consulting, Inc

400 Unicorn Park Drive

Woburn, MA 01801

Phone: 781-721-4098

Fax: 781-721-4073

Email: RSiegener@geiconsultants.com

Dr. Karen L. Skubal

U.S. Department of Energy

EM-22 Cloverleaf Building, Room 2129

1000 Independence Avenue, SW

Washington, DC 20585

Phone: 301-903-6524

Fax: 301-903-3617

Email: karen.skubal@em.doe.gov

Dr. Terri L. Stewart

Pacific Northwest National Laboratory

Post Office Box 99

MS:K 6-96

Richland, WA 99354

Phone: 509-375-4423

Email: terri.stewart@pnl.gov

Dr. Yi Su

Institute for Clean Energy Technology

Mississippi State University

205 Research Blvd.

Starksville, MS 39759

Phone: 662-325-3286

Fax: 662-325-8465

Email: su@icet.msstate.edu
Dr. Georgio Tachie

Florida International University

10555 West Flagler Stree

Miami, FL 33174

Phone: 305-348-6734

Ms. Brooke Traynham

Vanderbilt University

2600 Hillsboro Pike \#137

Nashville, TN 37212

Phone: 404-729-3366

Email: brooketraynham@msn.com

Dr. Mindy Vanderford

GSI Environmental Inc.

2211 Norfolk, Suite 1000

Houston, TX 77098

Phone: (713) 522-6300

Fax: (713) 522-8010

Email: mvanderford@gsi-net.com

Dr. Roelof Versteeg

daho National Laboratory

Energy Systems \& Technology Divisio

Post Office Box 1625

(dano Fill, ID 83415-2107

Fax: 208-526-9822

Email: Roelof.Versteeg@inl.gov

Mr. David Watson

Oak Ridge National Laboratory

Oak Ridge, TN 37831-6038

Email:watsondb@ornl.gov 


\author{
Dr. Jody Waugh \\ S.M. Stoller Corp. \\ $2597 \mathrm{~B} 3 / 4$ Road
Grand Junction, CO 81507 \\ Grand Junction, CO 8150 \\ Phone: 970-248-6431 \\ Dr. Bobbie-Jo Webb-Robertson \\ Dr. Bobbie-Jo Webb-Robertson
Pacific Northwest National Laboratory \\ P.O. BOX 999 \\ P.O. BOX
K7-90

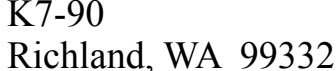 \\ Phone: (509) $375-2292$ \\ Fax: (509) $372-4720$ \\ Email: bobbie-jo.webb-robertson@pnl.gov
}

\section{Ms. Latrincy Whitehurst}

U.S. Department of Energy

19268 Ccircle Gate Drive \#3

Germantown, MD 20874

Phone: $301-903-7654$

Ms. Kathy Yager

Protection Agency

Technology Innovation and Field Services Division

11 Technology Drive (ECA/OEME)

North Chelmsford, MA 01863

Phone: 617-918-8362

Email: yagerkathleen@epa.gov

\section{APPENDIX B}

Summary of

Participant Evaluation Forms 
Long-Term Monitoring (LTM) Technical Forum

February 11-12, 2009

Summary of

Participant Evaluation Forms

This page intentionally left blank

The following is a compilation of the rated item grades and comments from an evaluation form completed by 15 of the Technical Forum's participants. This information will be used to plan future meetings of this type and scope.

Session Grade 1 (Lowest) to 5 (Highest)

Rating Items

Range

Mean Score

1. Facilities

3-5

4.20

2. Planning and Organization

3. Program Format

4. Effectiveness of Presentations

$3-5$

5. Clarity of Information Presented

6. Quality of Presentations

7. Time Devoted to Questions and Participant Discussion

8. Choice of Material Selected for

9. Overall Value of the Conference

- More information should have been sent out ahead of time on what the final product of the working group would be. In addition, ahead of time there could have been better definition of the scope of each group. Lastly, the information management system became too focused on specific hardware rather than effective use of the 


\section{- Needed more info before}

- Tools Group was a bit too large (20 - 25 people). Some of the presentations were not relevant to the discussion

- Well done! Interesting and valuable results.

- Hydrologist academic perhaps equal representation of disciplines giving presentations. In my session there was a strong bias in biology in the voting items generated by the break out groups showed this bias.

- Good examination of issues. Structured but not limiting. Liked the bucks exercise. I think it was good to include folks from outside DOE. Facility was great. Very nice conference rooms.

- Very effective. Could have more interface between groups before investment exercise. Also, could have a little more existing practice for kick off, other wise an A. Co-breakout chairs did a terrific job. Kudos Would be nice to have travel funds, this is out of my pocket.

- Needs facilitators. Better skeletal structure. Free Thinking is great but could have focused on end result of recommendations for investment. The money game was a great way to help that

- "Tools" Session was poorly led. Fewer presentations should have been given \& session leads should have had a pre-conceived plan for leading discussions. The group was too large for free-form discussions to be useful; gathering of the entire group after a couple hours of breakout discussions could have been useful (instead of the session leads going group-to-group).

\section{APPENDIX C}

List of

Ideal LTMS Attributes 


\section{Long-Term Monitoring System (LTMS) Breakout Session}

List of

\section{Ideal LTMS Attributes}

This page intentionally left blank
This list is a compendium of attributes provided by a range of participants in the workshop. Minimal editing was done to enhance clarity and to remove duplication, but in general this is the list as it was drafted by the participants.

\section{An ideal LTMS should}

- Be driven by fundamental understanding of critical processes;

- Measure and validate system performance;

- Use decision support tools, risk and site conceptual models to inform design and operation of LTMSs;

- Predict system behavior in the short and long term through combinations of analog sites, conceptual or numerical models;

- Periodically and structurally use data and novel insights to provide improvement to models of the system,

- Shift focus from compliance failure to system understanding and performance monitoring;

- Be designed to consider contaminated sites as an integral part of the overall site "ecology;"

- Be designed to provide critical system information and understanding (not just data); and

- Be linked into decision support systems (additional remedy, fix engineered systems, change predictions) and into risk estimates. 
This page intentionally left blank

\section{APPENDIX D}

LTM “Bucks" Investment Exercise Demographic Data Sheet 
This page intentionally left blank

Long-Term Monitoring Technical Forum

LTM "Bucks" Investment Exercise

Demographic Data Sheet

No.

Affiliation: (Check One)

Government ${ }^{\mathrm{a}}$ - $\quad$ Academia -

ancludes government contractors

Industry -

Other:

Focus: (Check One)

Basic Research - Applied Research Regulatory - ___ Other (Please specify)

Discipline: (Check One)

Geology/Hydrology - _ Geophysics -

Engineering - __ Other (Please specify):

Biology -

Chemistry - 
2009 DOE-EM Long-Term Monitoring Technical Forum

This page intentionally left blank 